University of Tennessee Health Science Center

UTHSC Digital Commons

\title{
Predictors of African American Women's Perceived Health Status in the Context of Caring for a Relative With End Stage Renal Disease
}

Dina Jo Byers

University of Tennessee Health Science Center

Follow this and additional works at: https://dc.uthsc.edu/dissertations

Part of the Nursing Commons

\section{Recommended Citation}

Byers, Dina Jo , "Predictors of African American Women's Perceived Health Status in the Context of Caring for a Relative With End Stage Renal Disease" (2008). Theses and Dissertations (ETD). Paper 36.

http://dx.doi.org/10.21007/etd.cghs.2008.0041. 


\title{
Predictors of African American Women's Perceived Health Status in the Context of Caring for a Relative With End Stage Renal Disease
}

\begin{abstract}
The purposes of this study of African American women who were family caregivers of persons with end stage renal disease (ESRD) were to: (1) identify their perceived health status and changes in perceived health status since assuming the caregiver role, (2) document the association between objective health status and caregiver age, (3) document the relationship between age and perceived health status, (4) identify demographic and subjective and objective health factors that predict perceived health status, and (5) identify their health promotion behaviors. The design for this study was a cross-sectional, descriptive correlational secondary analysis of data obtained from 75 African American women caring for a relative diagnosed with ESRD. These women participated in a larger study designed to investigate the predictors of health and burden in 120 family caregivers of patients with ESRD. The current study included data collected using the following instruments: The Caregiver Demographic Data Form, Caregiver's Perceived Health Form, Severity of Caregiver's Disease Scale, and the Center for Epidemiological Studies Depression Scale (CES-D). Data were analyzed using descriptive statistics, Spearman's correlation analysis, and stepwise multiple regression analysis. Overall, $28 \%$ of the caregivers rated their health as either fair or poor although most reported good health. Caregivers also reported several negative changes in health associated with the caregiving experience including decreases in exercise, energy, time for self, time for family and friends, and the amount/quality of sleep and increases in weight, and worry stress/tension. Forty-nine caregivers had scores of 0-15 indicating no signs of clinical depression; however, three caregivers $(4.0 \%)$ had scores of greater than 31 which indicated severe distress. The mean body mass index for caregivers was $31.2 \%$ indicating that on average this sample was obese. Reported health problems included hypertension (48\%) and diabetes (24\%). A significant weak positive correlation was found between perceived health status and caregiver age. Predictors of caregiver perceived health status indicated that five variables- number of prescription medications, number of physician office visits in the past 6 months, number of health problems, caregiver age, and total score of CES-D explained 31\% $(p=.000)$ of the total variance. Older caregivers on more prescription medications and with more provider visits, health problems and depressive symptoms reported the lowest perceived health status. The relatively small amount of perceived health status variance explained suggests that there are other factors that influenced the perceived health status of participating caregivers. The most common health behaviors reported by African American family caregivers were nutrition, exercise, modifying stress, spirituality/faith, following physician orders, and taking medication as ordered. Though participants reported multiple physical health problems most reported participating in health promotion activities and on average they perceived their health as good. There may be cultural and economic factors that explain this apparent dissonance between objective indictors of health and perceived health status of study participants. The health status of patients and families are the focus of nursing care and nursing research. End stage renal disease potentially affects the health of both patients and their caregivers. In this study caregivers reported multiple changes in health that could jeopardize their ability to continue to provide care. Findings from this study provide support for developing health promotion interventions that address the needs of understudied African American caregivers assisting persons with ESRD.
\end{abstract}

\section{Document Type}

Dissertation

\section{Degree Name}

Doctor of Philosophy (PhD) 


\section{Program}

Nursing

Research Advisor

Mona N. Wicks, PhD

\section{Keywords}

caregiver, health status, end stage renal disease, kidney disease, African American, women

\section{Subject Categories}

Medicine and Health Sciences | Nursing 


\title{
PREDICTORS OF AFRICAN AMERICAN WOMEN'S PERCEIVED HEALTH STATUS IN THE CONTEXT OF CARING FOR A RELATIVE WITH END \\ STAGE RENAL DISEASE
}

\author{
A Dissertation \\ Presented for \\ The Graduate Studies Council \\ The University of Tennessee \\ Health Science Center \\ In Partial Fulfillment \\ Of the Requirements for the Degree \\ Doctor of Philosophy \\ From The University of Tennessee
}

By

Dina Jo Byers

May 2008 
Copyright (C) 2008 by Dina Jo Byers All rights reserved 


\begin{abstract}
The purposes of this study of African American women who were family caregivers of persons with end stage renal disease (ESRD) were to: (1) identify their perceived health status and changes in perceived health status since assuming the caregiver role, (2) document the association between objective health status and caregiver age, (3) document the relationship between age and perceived health status, (4) identify demographic and subjective and objective health factors that predict perceived health status, and (5) identify their health promotion behaviors. The design for this study was a cross-sectional, descriptive correlational secondary analysis of data obtained from 75 African American women caring for a relative diagnosed with ESRD. These women participated in a larger study designed to investigate the predictors of health and burden in 120 family caregivers of patients with ESRD. The current study included data collected using the following instruments: The Caregiver Demographic Data Form, Caregiver's Perceived Health Form, Severity of Caregiver's Disease Scale, and the Center for Epidemiological Studies Depression Scale (CES-D). Data were analyzed using descriptive statistics, Spearman's correlation analysis, and stepwise multiple regression analysis. Overall, $28 \%$ of the caregivers rated their health as either fair or poor although most reported good health. Caregivers also reported several negative changes in health associated with the caregiving experience including decreases in exercise, energy, time for self, time for family and friends, and the amount/quality of sleep and increases in weight, and worry stress/tension. Forty-nine caregivers had scores of $0-15$ indicating no signs of clinical depression; however, three caregivers $(4.0 \%)$ had scores of greater than 31 which indicated severe distress. The mean body mass index for caregivers was $31.2 \%$ indicating that on average this sample was obese. Reported health problems included hypertension (48\%) and diabetes (24\%). A significant weak positive correlation was found between perceived health status and caregiver age. Predictors of caregiver perceived health status indicated that five variables- number of prescription medications, number of physician office visits in the past 6 months, number of health problems, caregiver age, and total score of CES-D explained $31 \%(\mathrm{p}=.000)$ of the total variance. Older caregivers on more prescription medications and with more provider visits, health problems and depressive symptoms reported the lowest perceived health status. The relatively small amount of perceived health status variance explained suggests that there are other factors that influenced the perceived health status of participating caregivers. The most common health behaviors reported by African American family caregivers were nutrition, exercise, modifying stress, spirituality/faith, following physician orders, and taking medication as ordered. Though participants reported multiple physical health problems most reported participating in health promotion activities and on average they perceived their health as good. There may be cultural and economic factors that explain this apparent dissonance between objective indictors of health and perceived health status of study participants. The health status of patients and families are the focus of nursing care and nursing research. End stage renal disease potentially affects the health of both patients and their caregivers. In this study caregivers reported multiple changes in health that could jeopardize their ability to continue to provide care. Findings from this study provide support for developing health promotion interventions that address the needs of understudied African American caregivers assisting persons with ESRD.
\end{abstract}




\section{TABLE OF CONTENTS}

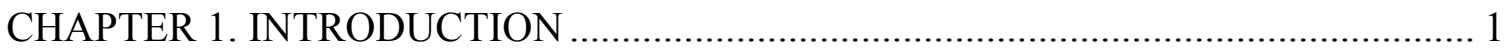

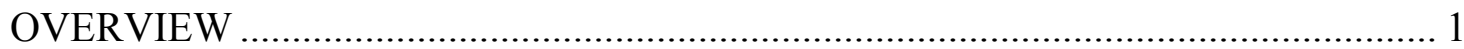

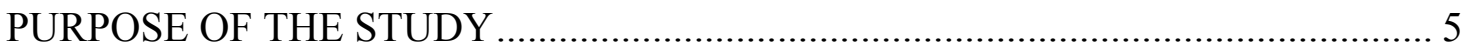

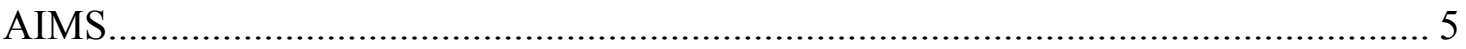

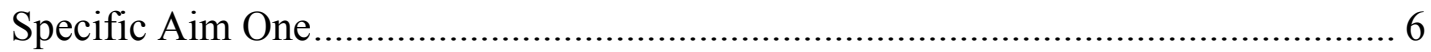

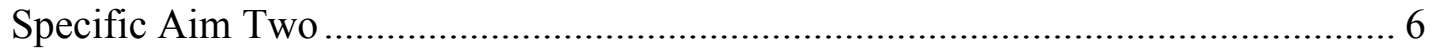

Specific Aim Three ................................................................................................. 6

Specific Aim Four......................................................................................... 6

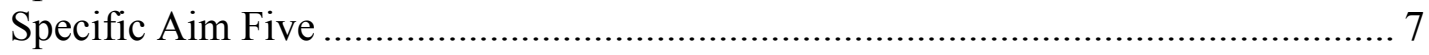

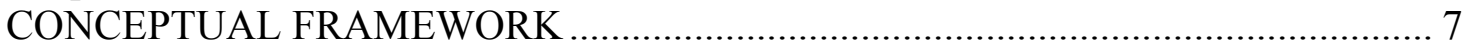

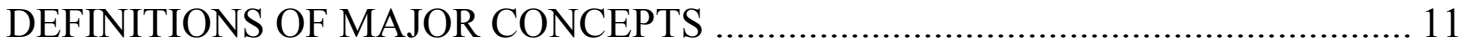

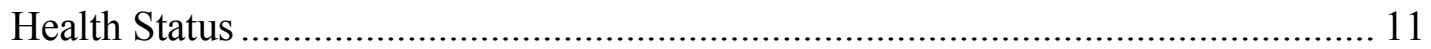

Demographic Factors ........................................................................................ 12

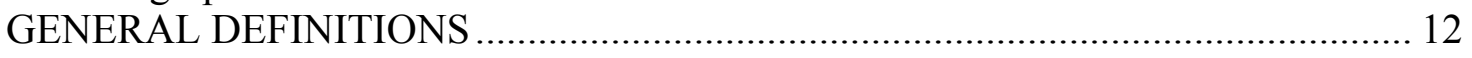

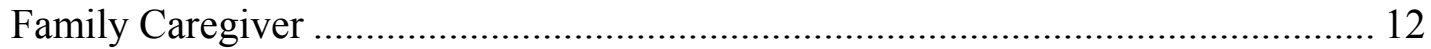

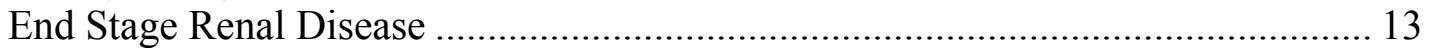

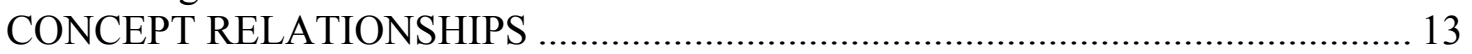

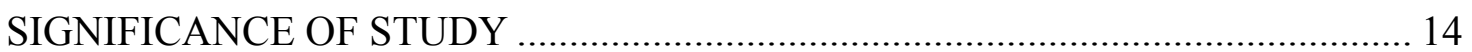

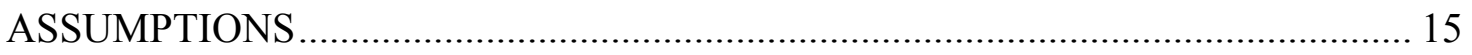

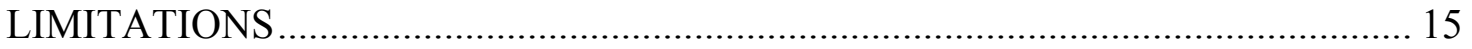

CHAPTER 2. REVIEW OF LITERATURE ........................................................... 17

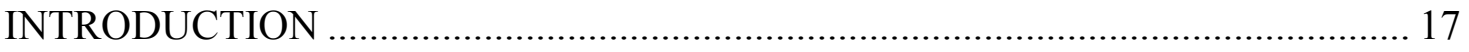

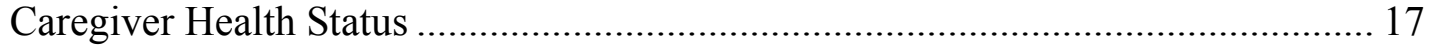

Perceived Health Status ................................................................................... 18

Perceived Change in Health Status ........................................................................ 18

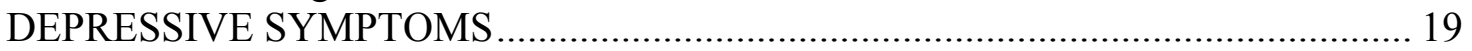

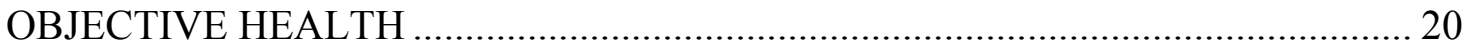

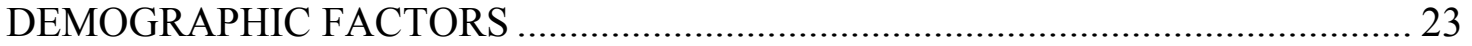

CAREGIVER AGE AND PERCEIVED HEALTH STATUS …................................ 24

DEMOGRAPHIC FACTORS AND OBJECTIVE AND SUBJECTIVE HEALTH

FACTORS AND PERCEIVED HEALTH STATUS ............................................ 25

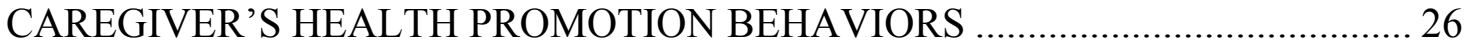

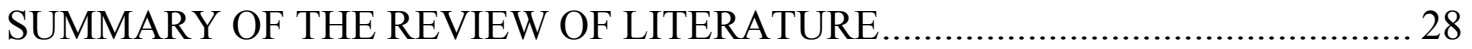

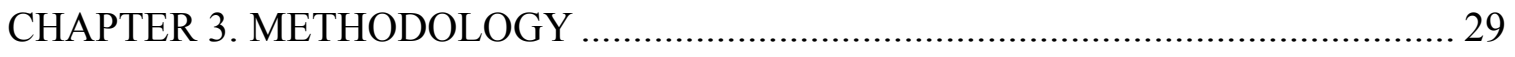

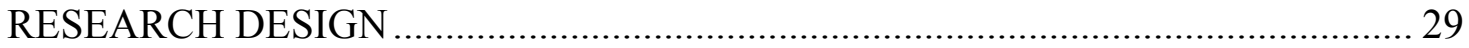

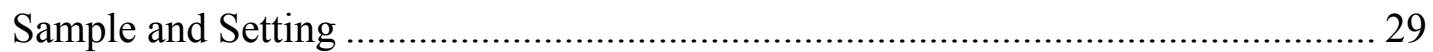

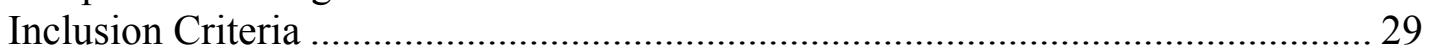

Exclusion Criteria ..................................................................................... 30

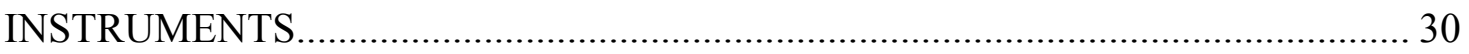


The Caregiver Demographic Data Form.................................................................. 30

Caregivers' Perceived Health Form.......................................................................... 31

Severity of Caregiver's Disease Scale .................................................................... 31

Center for Epidemiological Studies Depression Scale ............................................. 32

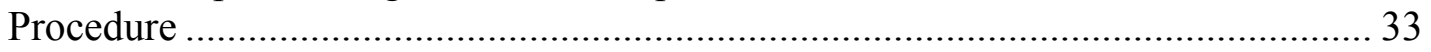

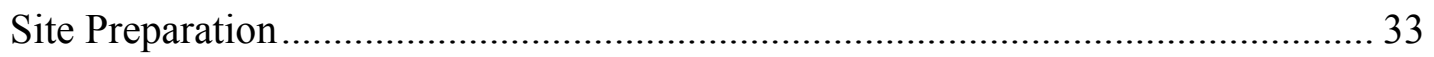

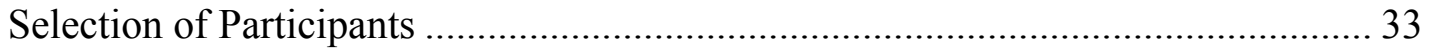

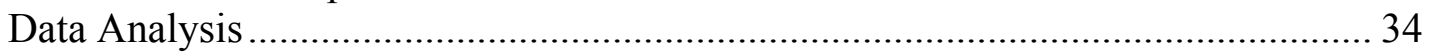

STATISTICAL ANALYSES OF SAMPLE DEMOGRAPHIC INFORMATION ..... 34

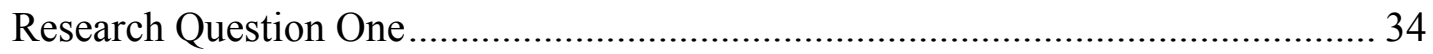

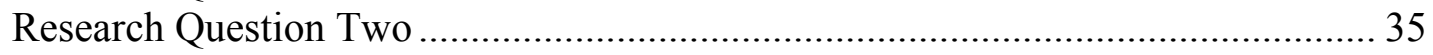

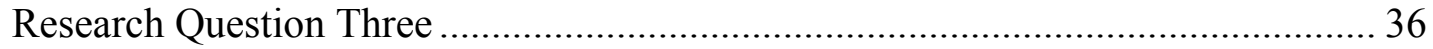

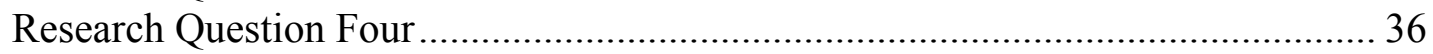

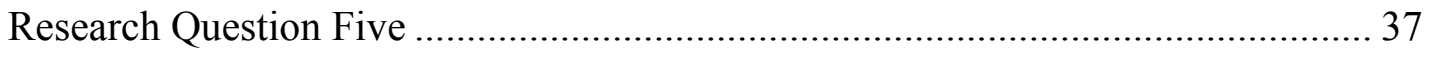

Protection of Human Participants ........................................................................... 37

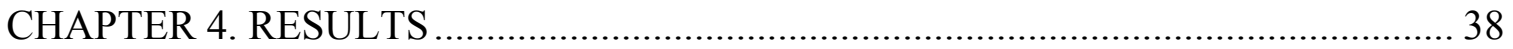

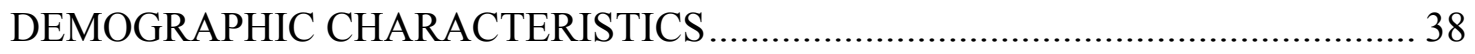

End Stage Renal Disease Caregiver Profile............................................................ 38

End Stage Renal Disease Patient Profile ........................................................... 38

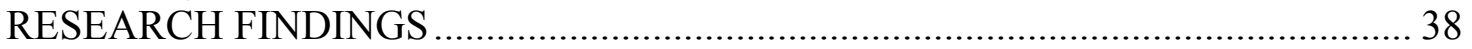

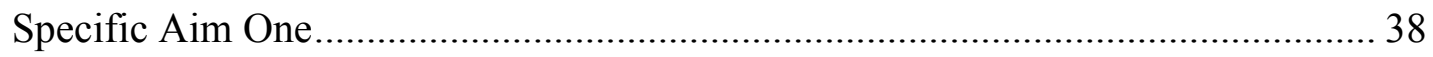

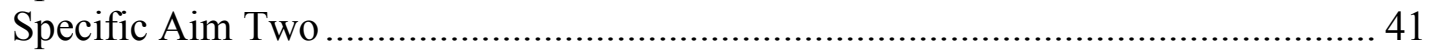

Specific Aim Three .................................................................................... 46

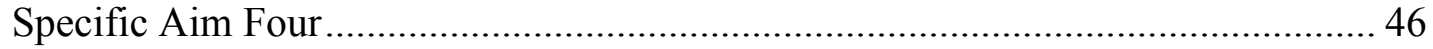

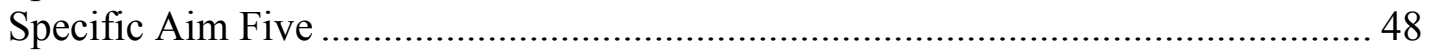

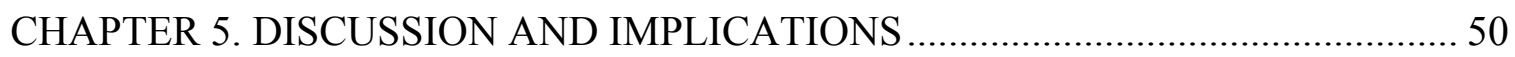

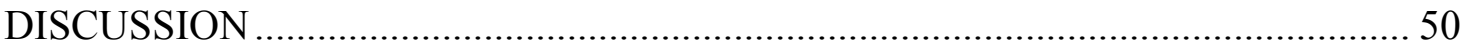

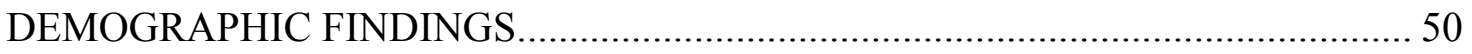

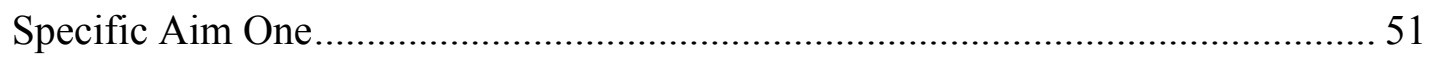

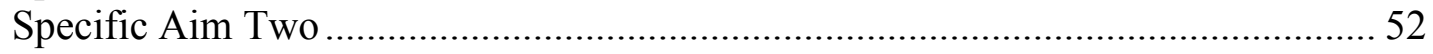

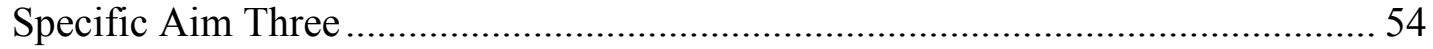

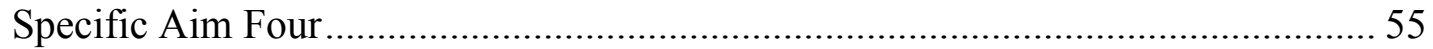

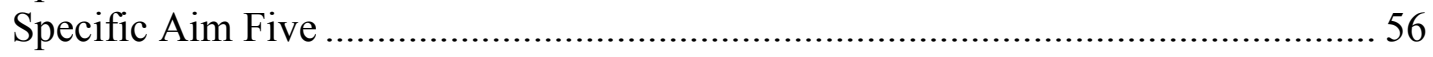

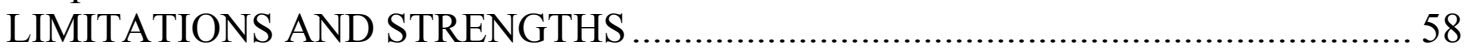

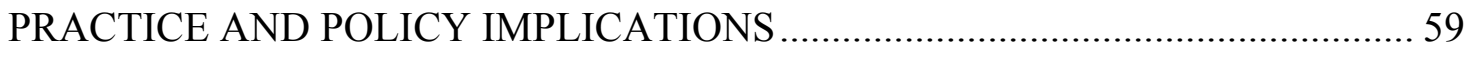

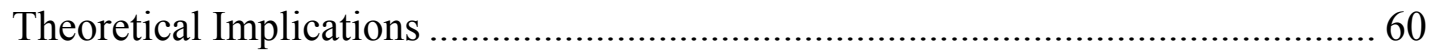

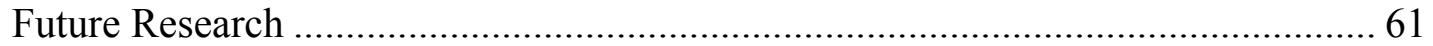

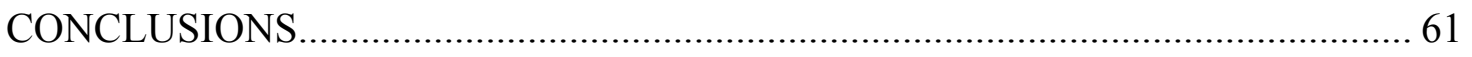

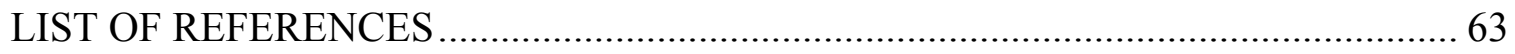

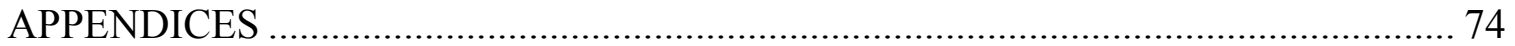


APPENDIX A. CAREGIVER DEMOGRAPHIC DATA FORM 75 APPENDIX B. CAREGIVERS' PERCEIVED HEALTH ASSESSMENT FORM ... 77 APPENDIX C. SEVERITY OF CAREGIVER'S DISEASE SCALE ........................78 APPENDIX D. CENTER FOR EPIDEMIOLOGICAL STUDIES-DEPRESSION SCALE (CES-D)... 84 APPENDIX E. LETTER OF APPROVAL - INSTITUTIONAL REVIEW BOARD 86

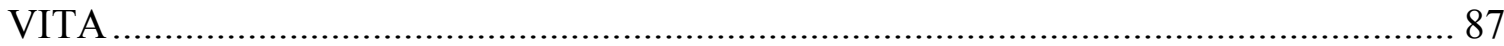




\section{LIST OF TABLES}

Table 1. Demographic Characteristics of African American Women Who Are

Caregivers of a Relative with End Stage Renal Disease

Table 2. Demographic Characteristics of Patients with End Stage Renal

Disease

Table 3. Perceived Health Status in Family Caregivers of Persons with End Stage Renal Disease.

Table 4. Changes in Health Status Associated with Caregiving

Table 5. Frequency and Percentage of Objective Health Factors Reported by Caregivers

Table 6. Frequency and Percentage of Health Promotion Behaviors Reported by

Caregivers 


\section{CHAPTER 1. INTRODUCTION}

\section{OVERVIEW}

Advances in medical technology and the rise in health care costs in the United States have lead to an increase in the number of persons with chronic diseases living longer and requiring home care versus acute hospitalization. More than 50 million adults currently provide care to relatives (National Family Caregivers Association, 2000). Even though family caregivers in the United States are not paid for their services, the care that they provide has an annual estimated value of 257 billion dollars (National Alliance for Caregiving and AARP, 2004). Persons with chronic illnesses may require assistance with performing activities of daily living and those related to disease management, particularly when the disease is physically debilitating or significantly impairs cognitive function. Often the spouse or daughter of persons with a chronic illness assumes the caregiver role (National Alliance for Caregiving and AARP, 2004).

Caregiver health status is a growing concern for clinicians and researchers because of the potentially detrimental consequences related to the role of informal caregiver. There is a strong agreement amongst researchers that caring for persons with chronic illnesses can lead to negative emotional and physical health outcomes for the caregiver (Harris, Thomas, Wicks, Faulkner, \& Hathaway, 2000; Schultz, Newsom, Mittlemark, Burton, Hirsch, \& Jackson, 1997). There have been many caregiving research studies conducted over the past two decades. Many of these studies focused on caregiver burden, stress, and the emotional distress that caregivers experience. Historically, many caregiving studies focused on the physical health status of caregivers more often than their health promotion behaviors. Although, increasingly the mental health of caregivers is being studied.

Physical health status is often measured by using a self-rated single item questionnaire, a physical symptoms checklist, or physiological measurements (i.e., body mass index (BMI), blood pressure, lipids levels). When measuring physical health it is imperative to include both subjective and objective indicators of health status.

Most subjective indicators of health status include self-reports. In the current study two self-reports measures were used to assess caregivers' perceived health status and perceived change in health status since becoming a caregiver. Researchers have found that self-rated health is a strong correlate of objective measures of health and predicts mortality better than either medical records or physician generated data (LaRue, Bank, \& Jarvik, 1979; Mossey \& Shapiro, 1982; Schulz \& Beach, 1999). Burstrom and Fredlund (2001) found that the risk of death was significantly higher among persons reporting poor compared to those reporting good self-rated health. Other investigators have concluded that perceived health evaluations are significant predictors of mortality even when physical health status is controlled (Idler, Kasl, \& Lempke, 1990; Kaplan, Barell, \& Lusky, 1988; Mossey \& Shapiro, 1982). Health behaviors of caregivers such as smoking, alcohol use, drug use, exercise and physical inactivity could have negative effects on both mortality and perceived health status of the caregivers (Idler \& Kasl, 
1991). Evaluations of perceived health status included self-reported changes in health status and health behaviors associated with taking on the caregiver role.

Self- report of change in health status or well-being is usually not assessed in behavioral research; however, theories of adaptation and other affective research have documented change in life circumstances as a predictor of emotional well-being (Suh, Diener, Fujita, 1996; Carver \& Scheier, 1990). Results of caregiving studies indicate that the caregiver's well-being may not change based on illness characteristics of the care recipient but rather the caregiver's appraisal of his or her situation and coping capacity (Gitlin, Winter, Dennis, \& Hauck, 2006). Caregivers' may experience changes in both physical health and mental health over time after assuming the caregiver role (McConnell, 1994; Pinquart \& Sorensen, 2005; Schultz et al., 1997).

Measurement of depressive symptoms is one indicator of caregivers' emotional health status. Depressive symptoms may also influence the way that the caregiver perceives his or her health status. Depressive symptoms and emotional health in general may also determine if the caregiver will participate in health promotion activities. There have been many caregiving studies conducted that examined the levels of depressive symptoms amongst caregivers. Schultz (1997) stated that caregivers, when compared to population norms or control groups, reported higher levels of depressive symptoms. There have also been several studies conducted that compared depressive symptoms among ethnically diverse caregivers. Some researchers report no difference in depression between White and African American caregivers (Cox \& Monk, 1996; Knight, Silverstein, McCallum, \& Fox, 2000), while Haley and colleagues (1995) report that White caregivers are significantly more depressed than African American caregivers.

Objective health indicators may also influence caregivers' perceived health status. Caregivers' perceptions of these health indicators and the meaning each caregiver associates with the indicator could also influence perceived health. Commonly used indicators of objective health include body mass index (BMI), number and type of prescription medications, and number of recent visits to a health care provider. Studies have shown that caregivers report higher rates of diabetes, arthritis, ulcers, and anemia than the general population (Bakas \& Burgener, 2002; Bakas, Pressler, Johnson, Nauser, \& Shaneyfel, 2006; McConnell, 1994; Pruchno \& Potashnik, 1989). Moreover, female caregivers report more chronic conditions such as arthritis, hypertension, and heart trouble than male caregivers (Pruchno \& Potashnik, 1989; Zhang, Vitaliano, \& Lin, 2006).

Weight gain is also a common health problem for female caregivers. Vitaliano and colleagues (2003) found that female caregivers experience a greater increase in weight than control groups. This increase in weight puts caregivers at increased risk for health problems such as, hyperlipidemia, hypertension, diabetes, cardiovascular disease, and arthritis. Many of these diseases, particularly diabetes and cardiovascular disease, are associated with an increased risk of depression, which is important as caregivers compared to non-caregivers experience higher levels of depression and lower levels of life satisfaction (Haley et al., 1987; Shua-Haim, Shi, Kuo, \& Smith, 2001; Zhang et al, 
2006). Research also indicates that caregivers compared to non-caregivers have higher levels of health care utilization as evidenced by both a greater number of prescription medications and a greater number of recent physician visits (Haley, Levine, \& Brown, 1987; Shua-Haim et al., 2001; Zhang et al., 2006).

The aforementioned studies provide important information regarding the mental and physical health of caregivers in relation to non-caregivers. Systematic examination of the health status of African American women who are caregivers is critical as caregiver health studies seldom include these women.

Research conducted across a variety of chronic illness populations has shown that there are many factors associated with the negative effects of caregiving. Age, income status, level of education, and length of caregiving are independent and significant correlates that can negatively affect the health status of informal caregivers, particularly in older caregivers (McDonald, Brennan, \& Wykle, 2005; Schultz \& Beach, 1999; Schulz $\&$ Beach, 1999). Studies have shown that age may or may not affect the health status of the caregiver. In two studies related to caregiver age and health, Shultz $(1995,1999)$ found non-significant relationships between age and health status. However, Harwood and colleagues (2000) examined factors associated with perceived health status of 64 White family caregivers of community dwelling Alzheimer's disease patients. The researchers concluded that poor self-rated health was predicted by older caregiver age and greater depressive symptoms reported by the caregiver. Developmentally older adult caregivers compared to younger adult caregivers may expect to assume the role of caregiver as chronic illness and disability are often expected consequences of aging. Younger adult caregivers often have multiple competing roles that include parenting, head of household, employee, and possible caregiver to multiple persons (Cox, 1996; Bakas \& Burgener, 2002).

Results of several studies have shown that along with age there are other sociodemographic factors are often independently and significantly related to health outcomes. The literature reveals that caregivers with lower education and income levels experience worse health outcomes when compared to caregivers with better resources (DilworthAnderson, Goodwin, \& Williams, 2004; Schultz et al., 1997; Sorensen \& Pinquart, 2005). Kubzansky, Berkman, Glass and Seeman (1998) also found that higher levels of education were consistently associated with higher levels of emotional and physical health. Several studies report that individuals who are married and employed have increased social and financial resources (Brody, Litvin, Hoffman, \& Kleban, 1992).

Many of the informal caregiver studies conducted focused on caregivers of cognitively impaired persons (Alzheimer's disease) and caregivers of persons with chronic illnesses such as stroke, arthritis, chronic obstructive pulmonary disease, and cancer (LoGuidice, Kerse, Brown, \& Gibson, 1998; Mace \& Rabins, 2001; Rosenman, Le Brocque, \& Carr, 1994; Schultz \& Beach, 1999; Schulz \& Beach, 1999). Little research has been done on the health status of African American women caring for patients with ESRD despite its high prevalence rate and devastating effects. 
End stage renal disease is a chronic illness that affects African Americans disproportionately. The United States Renal Data Systems (USRDS, 2003) report indicates that more than 100,000 new patients began therapy for ESRD in 2003, which represents a 2 percent increase compared to the 2002 rate. The incidence rate among African Americans is nearly four times higher than the incidence rates among White Americans (USRDS, 2006). By the year 2010, over 650,000 individuals will be diagnosed with ESRD. Patients who are diagnosed with the disorder require dialysis treatment or kidney transplant in order to survive. Some patients with ESRD receive continuous ambulatory peritoneal dialysis (CAPD), which can be performed at home. This method of dialysis must be performed four times a day, every day, and each session last approximately 1 hour. In-center hemodialysis $(\mathrm{ICH})$ provides an alternative to CAPD. Most patients receiving hemodialysis receive treatment at a dialysis center three times a week and this treatment method usually last four hours (National Institutes of Diabetes \& Digestive \& Kidney Diseases, 2006). A few patients with ESRD are treated with home peritoneal hemodialysis (HPD) or home hemodialysis (HH). Many patients who receive dialysis therapy require assistance from a family caregiver at some point during their disease trajectory due to the detrimental affects of ESRD and its complications. Unintentional weight loss, nausea and vomiting, greatly decreased urine output or anuria, and fatigue are common symptoms. Many of these patients, over time, also experience varying degrees of cognitive impairment (Hopkins, 2005). Research documents that dialysis patients report feelings of anger, depression, and fatigue (White \& Greyner, 1999). Many patients with ESRD experience complex medication schedules, dietary and fluid restrictions, and financial burdens which result in major lifestyle changes (Calvin, 2004).

Risk factors for developing ESRD include hypertension, diabetes, and obesity. Diabetes remains the most common cause of ESRD while hypertension is the second most common cause of the disorder. Risk factors for ESRD include familial and genetic factors, the length of time a person has had diabetes, hyperglycemia, hypertension, and hyperlipidemia. Studies have shown that African Americans are more likely to experience hypertension, retinopathy, and ESRD compared to White Americans (Konen \& Summerson, 1999).

The role of caregiver can lead to stress and burden and this is true for caregivers of persons with ESRD (Belasco \& Sesso, 2002; Harris et al., 2000; Sales, 2003). Family caregivers of patients with ESRD, many of whom are African American women, often have little or no time to focus on their own health needs and concerns (Campbell, 1998; Harris et al., 2000; Wicks, Milstead, Hathaway, \& Cetingok, 1997). In order for these African American women to continue to provide care to patients with ESRD, their health must be maintained. Research has also shown that the health status of African American women is generally poor compared to other ethnic groups (Haley, Gitlin, Wisniewski, Mahoney, Coon, \& Winter, 2004). Moreover, African American women, in general, and women who are caregivers in particular are less likely to participate in health promotion activities (Acton, 2002). The combined risk of being an African American woman and an informal caregiver of a relative with ESRD likely increases the risk of poor health 
outcomes and inadequate participation in health promotion activities (Flaskerud \& Lee, 2001).

Female caregivers report more often than male caregivers that they suffered from a lack of well being, and decrease in psychosocial health and overall self-rated health (Schultz et al., 1997). Women who are caregivers often report depressive symptoms, overall health problems, and lower perceived health status than non-caregivers (Schultz et al., 1997). Even though research unequivocally indicates that women are most often the primary caregivers of chronically ill persons, the populations studied have been primarily Caucasian women. Fewer studies have included African American women as caregivers and few researchers have examined the health status of these women.

African American populations disproportionately face health risks that includes racism and poverty (Flaskerud, Lesser, Dixon, Anderson, Conde, Kim et al., 2002); however, research indicates that African Americans often utilize health services less than other ethnic groups despite this increased health risk of poorer health outcomes (McDonald et al., 2005). Research is needed to understand the health of African American women who are caregivers and test interventions that improve their health outcomes. It is also important to study the health status of African American women caregivers because caregiving responsibilities may contribute to poor self-care behaviors, which further jeopardize the health of these women who provide an important service to their families and the U.S. health care system.

\section{PURPOSE OF THE STUDY}

Historically caregiving research has focused on caregivers of persons with cognitive impairment or chronic illnesses with primarily physical manifestations. Findings from these studies, which typically focus on White caregivers, are important because these studies suggest that across patient populations, caregivers often experience impaired physical and mental health status associated with the role. African American female family caregivers of persons with ESRD likely experience similar health impairments; however, studies are needed to document the validity of this assertion. Therefore, the purposes of the present study of African American women who are family caregivers of persons with ESRD was to 1) identify their perceived health status, changes in perceived health status since assuming the caregiver role, and level of depressive symptoms; (2) document objective health factors and the association between objective health factors and age; (3) document the relationship between age and perceived health status; (4) identify demographic and subjective and objective health factors that predict perceived health status; and (5) identify their health promotion behaviors.

\footnotetext{
AIMS

The aims that guided this study were derived from the literature and are described next. Associated research questions follow each study aim.
} 


\section{Specific Aim One}

In Specific Aim One we identified the level of perceived health status reported by of African American women who are family caregivers of persons with ESRD by recording subjects' answers to the questions below.

- What is the perceived health status reported by African American women who are family caregivers of persons with ESRD?

- What is the perceived change in health status since the caregiving role began as reported by African American women who are family caregivers of persons with ESRD?

- What is the level of depressive symptoms reported by African American women who are family caregivers of persons with ESRD?

\section{Specific Aim Two}

In Specific Aim Two we documented the objective health factors and the relationship between objective health factors and age of African American women who are family caregivers of persons with ESRD with subjects' answers to the questions below.

- What is the body mass index (BMI) and the association between BMI and age of African American women who are family caregivers of persons with ESRD?

- What is the number of prescription medications and association between number of prescription medications and age of African American women who are family caregivers of persons with ESRD?

- What is the number of physician office visits and the association between number of physician office visits and age of African American women who are family caregivers of persons with ESRD?

- What is the number of health problems and the association between number of health problems and age of African American women who are family caregivers of persons with ESRD?

\section{Specific Aim Three}

In Specific Aim Three we documented the relationship between the perceived health status and age as reported by African American women who are family caregivers of persons with ESRD.

\section{Specific Aim Four}

In Specific Aim Four we identified demographic factors (age, level of education, and socioeconomic status) and objective and subjective health factors that predicted the 
perceived health status as reported by African American women who are family caregivers of persons with ESRD.

\section{Specific Aim Five}

In Specific Aim Five we documented the health promotion behaviors reported by African American women who are family caregivers of persons with ESRD.

\section{CONCEPTUAL FRAMEWORK}

Conceptual frameworks are designed to guide methodological decisions and aid the interpretation of study results. There are several conceptual frameworks identified in the literature that are used to explain health outcomes in informal caregivers (Cox \& Monk, 1996; Turner \& Catania, 1997). The stress-process theory (Pearlin, Mullan, Semple, \& Skaff, 1990) and stress and coping theory (Lazarus \& Folkman, 1984) are two examples of conceptual models often used to guide caregiving research. Most research studies that incorporate these and other conceptual models are based on White middle class caregivers (Kuhlman, Wilson, Hutchinson, \& Wallhagen, 1991). However, Flaskerud's Vulnerable Populations Model provides a framework specific to African American women who are family caregivers. The Vulnerable Populations Model considers female caregivers as a vulnerable or an at-risk group for increased health problems (Flaskerud \& Winslow, 1998).

The conceptual framework in the current study (see Figure 1) focuses on demographic factors (age, level of education, marital status, and socioeconomic status) and subjective (perceived health status, perceived change in health status, and depressive symptoms) and objective health indicators (BMI, number of prescription medications, number of physician office visits, and number of health problems) as correlates of health status in a sample of African American women who are caregivers of persons with ESRD. Specifically, the framework that guided this study influenced conceptual definitions used and the instruments selected to measure study variables and will influence interpretation of study findings. The conceptual framework for the current study was based on Flaskerud's Vunerable Populations Model (Flaskerud \& Winslow, 1998) because the focus of the study was on African American women who were caregivers at risk for impaired health status.

The word vulnerability is derived from the Latin word, vulnerare, meaning "wound" (Aday, 1993). In the past the most common uses of the word vulnerability reflect susceptibility to health problems, harm, or neglect (Phillips, 1992; Rogers, 1997). An important concept included in the meaning of vulnerability is risk (Aday, 1994). Women and ethnic people of color are commonly considered vulnerable to an increased risk of poor health (Flaskerud \& Winslow, 1998). Thus, African American female caregivers are at risk not only because of their role as informal caregivers but also because they are women and persons of color. Female informal caregivers can also be considered a social group that is vulnerable to poor health outcomes due to the limited 


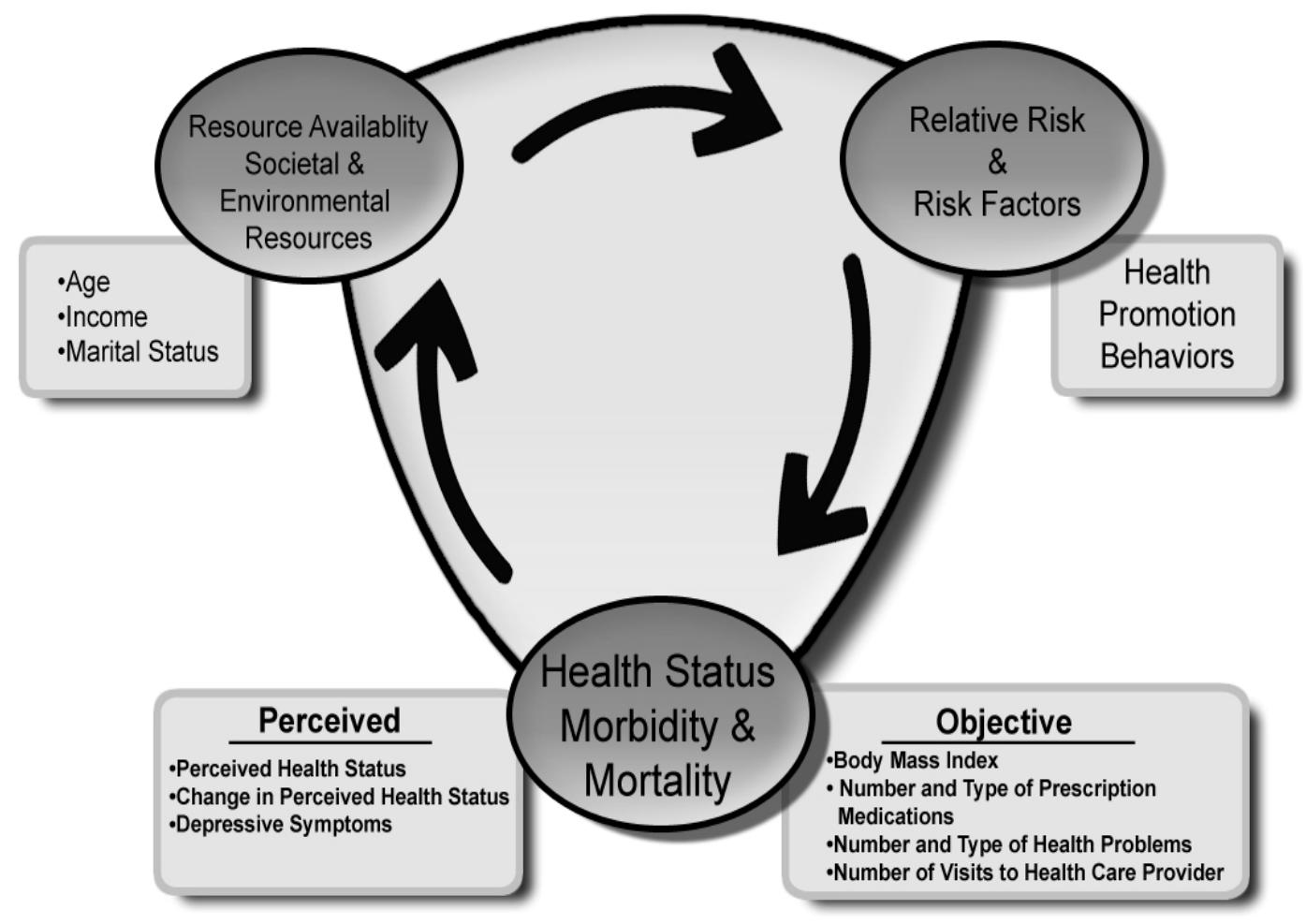

Figure 1. Vulnerable Populations Model.

Reprinted with permission from: Flaskerud, J., \& Winslow, B. (1998). Conceptualizing vulnerable populations' health-related research. Nursing Research, 47(2), 69-78. 
amount of resources available to them, as well as, the increased exposure to conditions (length of caregiving, ethnic minority status, racism, and being a women) that can contribute to poor health status.

The Vulnerable Populations Model is composed of interrelationships among resource availability, relative risk, and health status (Aday, 1994; Flaskerud \& Winslow, 1998). The model explains that resource availability includes socioeconomic and environmental resources. The concept of relative risk is explained by the ratio of poor health of people who lack resources and are exposed to the risks compared to people who receive resources and are not exposed to risk (Flaskerud \& Winslow, 1998). The health status is determined by disease prevalence and morbidity and mortality rates amongst the community.

African American women are at risk for increased morbidity and mortality because they are disproportionately poor, members of a minority group, and informal caregivers. African American women caregivers often lack resources which further increase their risk for poor health status. The absence of resources is particularly problematic because ESRD often results in disability and loss of income for the affected person. African American women may experience lack of access to quality care (Williams \& Wilson, 2001) or may lack access to insurance coverage (Sotomayor \& Randolph, 1988). The absence of these resources could contribute to their vulnerability.

Three fundamental relationships exist in the Vulnerable Populations Model (see Figure 1). The first relationship exists between resource availability and relative risk. The model suggests that if there is a limitation of resource availability than there is an increased in the relative risk (Flaskerud \& Winslow, 1998). Flaskerud and Winslow also explain that an individual's risk will vary based on opportunities and resources. Within the model personal traits and social status (age, sex, race, and ethnicity), relationships with people (family structure, marital status, and social networks), environmental factors (jobs, income, and housing), and other associated factors (violence and/or crime) will change an individual's risk for poor health (Aday, 1993, 1994; Flaskerud \& Winslow, 1998; Leight, 2003). Often women live in poverty with low social status and jobs paying salaries 30-40\% less than men's salaries (Bureau of the Census, 2005). Compared to White women, African American women experience more than twice as much poverty and unemployment (Bureau of the Census, 2005). Research has shown that social and economic resources are limited for women and in particular for ethnic women of color (Aday, 1993; Bureau of the Census, 2005).

Socioeconomic and environmental resources strongly influence a person's ability to avoid risk factors and decrease the occurrence of disease and its consequences (Aday, 1993). Being poor, unemployed, and having lower levels of education are all factors that demonstrate a lack of resources which are linked to poor health (Adler, Boyce, Chesney, Folkman \& Syme, 1994; Link \& Phelan, 1996). This study explored demographic factors that predict perceived health status as the study framework suggested that these factors influenced health status. 
The second important relationship within the model exists between the variables relative risk and health status. According to the model some groups are more vulnerable to risks, such as poor persons and minority populations, which can lead to poor health status. According to Aday (1993), "The vulnerability hypothesis argues that negative or stressful life-events (such as employment or a related loss of income or personal resources) hurts some people more than others" (p. 5). Caregiving for some women is a negative life event. The concept of relative risk means that there is always a chance that an individual may experience negative health outcomes at certain times during their lives; however, the model describes that certain individuals and groups are more at risk than others with no regard to timing of the stressful events.

Women also often lack social status and power which further increases their risk of poor health status. African American women generally have less social status and power than women of other ethnic groups. According to the Bureau of the Census (2005) female-headed households have fewer social connections, economic resources, and often lack access to community resources. African American women are more often heads of households than other women. Ethnic women of color who are caregivers have access to fewer resources than Caucasian caregivers (Flaskerud \& Tabora, 1998; Picot, 1995).

Research also indicates that African Americans when compared to Caucasian Americans are more likely to experience chronic diseases including hypertension, retinopathy, and ESRD (Konen \& Summerson, 1999). Studies have shown that caregivers, in general, report higher rates of diabetes, arthritis, ulcers, and anemia than the general population (Bakas \& Burgener, 2002; Bakas, Pressler, Johnson, Nauser, \& Shaneyfel, 2006; McConnell, 1994; Pruchno \& Potashnik, 1989). Moreover, female caregivers experience and report more chronic conditions (arthritis, hypertension and heart trouble (Pruchno \& Potashnik, 1989; Zhang, Vitaliano, \& Lin, 2006). Research also indicates that African American women, in general, and women who are caregivers in particular are less likely to participate in health promotion activities (Acton, 2002).

The final relationship in the model exists between health status and resource availability (Flaskerud \& Winslow, 1998). The model explains that female informal caregivers are vulnerable to poor health outcomes and poor health status because they have limited resources and are exposed to certain risk factors. Research also has shown that women of color who are caregivers have access to fewer resources than Caucasian caregivers (Flaskerud \& Winslow, 1998; Picot, 1995). Female informal caregivers often experience poverty, unemployment, lower levels of education, and a lack of support services. By simply being African American female caregivers this population could be at risk for poorer health status and negative health related outcomes.

The current study examined demographic factors that predict perceived health status. Demographic factors that were examined include income, employment, marital status, and level of educational attainment. The framework proposes that a lack of socioeconomic and environmental resources contributes to the vulnerability of women. Poverty, unemployment, and lower levels of education have been linked to poor health (Adler et al., 1994). As stated previously, African American women experience twice as 
much poverty and unemployment as White women (Bureau of the Census, 2005). Relative risk factors that were examined included health promotion behaviors of African American women who are family caregivers of persons with ESRD. As stated previously, African American women are less likely to participate in health promoting behaviors. The study also examined the perceived health status, perceived change in health status since becoming a caregiver, and perceived depression symptoms as indicators of perceived health status. The objective health indicators that were examined included BMI, number and type of prescription medications, number and type of reported health problems, and number of visits to a health care provider in the past six months.

African American women caregivers of persons with ESRD are a vulnerable population because they often experience multiple vulnerabilities such as poverty and racism. When the added task of caregiving is assumed these women may be required to quit their jobs, which further increases their financial strain reducing resources and increasing their vulnerability to poor health status. This is particularly true if the patient with ESRD is disabled and no longer employed.

The Vulnerable Populations Model guided this study because the model explains that diminished resources (lack of social support, poverty), relative risk (informal caregiver, female, ethnic minority), and health status are significantly related concepts. The study framework included factors that could influence caregiver health outcomes. This study identified demographic and subjective and objective health factors that predict perceived health status.

\section{DEFINITIONS OF MAJOR CONCEPTS}

For the purpose of the current study, the following concepts and definitions were used.

\section{Health Status}

There are many definitions of health. Pender, Murdaugh, and Parsons (2002) define health as the "actualization of inherent and acquired human potential through goal directed behavior, competent self-care, and satisfying relationships with others, while adjustments are made to maintain structural integrity and harmony with relevant environments" (p. 22). According to the World Health Organization (WHO, 1948) health is a state of complete physical, mental, and social well-being, and not merely the absence of disease or infirmity. Health is subjective and individualistic. It is what the individual perceives it to be. Health status for the purpose of this study was defined as the perceived and objective information about personal well-being as reported by the individual. Health status was measured by the caregiver's perceived health status, the caregiver's perceived change in health status since becoming a caregiver, the caregiver's level of depressive symptoms, caregiver's body mass index (BMI), number and type of health problems, and number and type of medications currently prescribed to the caregiver. 
Perceived Health Status. Pender and colleagues (2005) defined perceived health status as a psychological personal factor that can either directly or indirectly affect health behavior when current health status is relevant to performing health related actions. For the purpose of this study perceived health status was measured using a self-reported Caregiver's Perceived Health Assessment Form which is a single-item, self-rated health score. Response categories for the self-administered scale range from 1 (excellent) to 5 (poor) the higher the score the poorer the health status. Included in the evaluation of perceived health status was participants' reported levels of depressive symptoms. The participant's level of depressive symptoms was operationally assessed as the Center for Epidemiological Studies Depression Scale (CES-D) (Radloff, 1977) score. The CES-D score measures the participant's current level of depressive symptoms.

Objective Health Status. Objective health refers to a state of well-being reflective of bodily function. Objective health status was assessed using the Phillips and Rempusheski's (1986) Severity of Caregiver's Disease Scale. This scale includes subscales for symptoms in different organ systems. Respondents report past and current health problems, numbers of prescription medications, number of days in hospital, number of doctor visits, and changes in health since becoming a caregiver. Objective health status for this study was assessed by the participants BMI, number and type of health problems, number and type of medications prescribed to participant, and number of physician office visits. Body mass index was operationally defined using the Center for Disease Control formula, which is based on height by weight. The participants past and current health problems, numbers of prescription medications, number of days in hospital, number of physician office visits, and changes in health since becoming a caregiver was determined using participant's self-reported data.

\section{Demographic Factors}

Demographic factors that were assessed in this study included age, level of education, income, and marital status. These variables are factors that may influence perceived health status. All predictors were determined as reported by the study caregivers. Age was operationally defined by subtracting the participant's date of birth from the year that they entered the study. Level of education, marital status, and income were determined using the Caregiver Demographic Data Form. Level of education was operationally defined by the number of years participants' attended school. Marital status was operationally defined by married, single, divorced, or separated. Income was operationally defined by the amount of money participants' made annually.

\section{GENERAL DEFINITIONS}

\section{Family Caregiver}

Family caregivers can be defined as any person who provides "informal" care to an ill or disabled family member or friend of any age. According to Campbell (1998), the 
structure of families is changing rapidly. Families are more nontraditional in composition and more diverse with regard to culture, ethnicity, and socioeconomic status. Compared to White families, a great proportion of African Americans are cared for at home. In order to identify the primary caregiver for this study, patients were asked, "If you became unable to care for yourself, who would you ask to take care of you?"

\section{End Stage Renal Disease}

A person is diagnosed with ESRD when they have developed chronic renal failure and require chronic kidney replacement treatment of any form such as in-center hemodialysis (ICH), home hemodialysis (HH), or home peritoneal hemodialysis (HPD) or renal transplant in order to sustain life (National Institutes of Health, 2006). An inclusion criterion for this study is that the participant (i.e., caregiver) must be providing care to someone who has been diagnosed with ESRD. Thus, only caregivers of patients receiving $\mathrm{ICH}, \mathrm{HH}$, and $\mathrm{HPD}$ are included in this study. A diagnosis of ESRD was operationally defined by the self-reported need of the patient for chronic dialysis at one of the three study dialysis centers.

\section{CONCEPT RELATIONSHIPS}

African American women may experience poor health status not only because they are women but also because they are members of an ethnic minority group. Specific factors that influence caregiver's health status include lack of resources and exposure to conditions that contribute to poor health outcomes. Variables within the study framework are associated with caregiver health status. The caregiver's perceived health status, objective and subjective factors that influence health status and demographic characteristics are the variables that were measured in this study. The current study did not directly test the variables of the Vulnerable Populations Model but focused on a vulnerable populations' health status and the demographic factors and subjective and objective health factors that influenced their health status. The factors assessed included resources (i.e., income and education) that are key variables within the model, relative risk of disease (i.e., BMI, depressive symptoms, etc.) and influenced perceived health status in these women.

Caregiver demographic characteristics that have been found to influence caregiver health status include age, race, relation to patient, gender, marital status, SES, employment status, education, hours spent providing care, caregiving duration, and other caregiving responsibilities other than the patient (Han \& Haley, 1999). Many studies suggest that female family caregivers rate their health as fair or poor (Haley et al., 2004; Schultz \& Beach, 1999). Other studies suggest that poverty, unemployment, and lower levels of educational attainment are also related to poor health status (Adler et al., 1994). African American women compared with Whites, experience more than twice as much poverty and unemployment (Bureau of the Census, 2005). Research has also shown that limited resources and increased exposure to risks result in greater morbidity (Schultz et 
al., 1997). These findings suggest that African American women who are caregivers of persons with ESRD may experience negative health outcomes.

\section{SIGNIFICANCE OF STUDY}

Approximately $30 \%$ of persons suffering from ESRD are African Americans (National Institutes of Health, 2006). African American caregivers who provide care to patients with ESRD may face many challenges when caring for these patients because of their complex needs and the debilitating nature of the disease and its associated complications. Co-morbid cardiovascular disease and diabetes are common in patients with ESRD, which over time can significantly impair patients' functional status and independence (Konen, Summerson, Bell, \& Curtis, 1999). Moreover, mood disturbances such as depression are common and further impair patient functioning. Many patients with ESRD may need assistance with activities of daily living due to the detrimental effects of this disease. African Americans often receive dialysis therapy later in the course of the disease and therefore may be more debilitated than other ethnic groups when dialysis is initiated (USRDS, 2007). Fewer of these patients receive a kidney transplant and when they do, they often receive a renal allograft after several years on the transplant waiting list.

Independently being African American or a female caregiver is associated with negative health behaviors and poor physical and mental health outcomes (Haley et al., 2004). This caregiver population faces health risks that can lead to poor health outcomes particularly since African Americans often under utilize health services and caregivers often forgo self-care in favor of caring for their relatives (Dilworth-Anderson et al., 2004).

Caregivers of these patients are usually women (spouses or daughters). Many of these women experience changes in their own health status due to their caregiver responsibilities. These caregiving responsibilities can lead to depression, poor health habits, and in general poor health status (Haley et al., 2004; Schultz et al., 1997). The knowledge gained by conducting this secondary data analysis could provide health care providers with new information to develop resources and interventions that improve the health status of African American female caregivers. The caregiver must be welleducated and empowered to make changes necessary to improve health outcomes. Moreover, health care providers must be well trained and informed about the caregivers' perceptions of their health status and health promotion behaviors to provide a partnership that leads to improved health outcomes of the caregiver.

Improving the health status of these caregivers could in turn assist these caregivers to provide better care to family members with ESRD. Even though published research indicates that women are the primary caregivers the population studied has been primarily Caucasian women. Few studies include African American women caregivers and examine their health status; thus, this study is sorely needed. 


\begin{abstract}
ASSUMPTIONS
The following assumptions were made for this study based on the conceptual framework, published literature, the investigator's experience with the study population, and study design.

1. Caregivers were aware of their health history and accurately evaluated their health using the single item caregiver health instrument. Researchers have found selfevaluation of health to be a significant predictor of mortality (Schultz \& Beach, 1999).

2. Providing care to a family member with ESRD can be detrimental to the caregiver's health. African American women who are caregivers may experience poorer health status due to several factors. They often experience lower paying jobs or unemployment, racism, and lack of access to resources all of which could negatively affect health status.

3. Concepts embedded within the conceptual model were relevant for African American women in this study who were caregivers of person with ESRD. Study participants may be at risk for poor health because many are poor, female, caregiver, and all are members of an ethnic minority group. African Americans compared to Caucasian Americans experience more than twice as much poverty and unemployment (Bureau of the Census, 2005). African American women often lack access to health care services and have limited access to economic and community resources (Aday, 1993).
\end{abstract}

\title{
LIMITATIONS
}

The proposed study was a secondary data analysis of data from a larger study. Conducting a secondary data analysis can lead to threats to internal and external validity (Burns \& Grove, 2004) including the lack of control of confounding variables. In spite of these limitations, this study may provide health care providers with new information to develop resources and interventions that will improve the health status of African American female caregivers.

The data were collected during one period in time thus it does not reflect the totality of the caregivers' experiences over time. Participating caregivers had different levels of caregiving experiences, which could potentially decrease the external validity of the study findings if the sample was not representative of the ESRD African American female caregiver population.

Most of the participants were from the metropolitan area; therefore, the results of the study may not be reflective of the experiences reported by individuals who live in a rural area at the time the study was conducted. 
Phillips and Rempusheski's (1986) Severity of Caregiver's Disease Scale has not been validated in caregivers of persons with ESRD.

Caregivers who are severely stressed, depressed, or burdened may not be represented in this study. Caregivers who experienced severe burden and stress from their day-to-day caregiving routines coupled with other responsibilities may not have participated in the primary study.

Caregivers who could not read or write were not represented in this study. 


\section{CHAPTER 2. REVIEW OF LITERATURE}

\section{INTRODUCTION}

There have been many informal caregiver studies conducted. Most of these studies focused on caregivers of cognitively impaired persons (Alzheimer's disease) and caregivers of persons with chronic illnesses such as stroke, arthritis, chronic obstructive pulmonary disease, and cancer (LoGuidice et al., 1998; Mace \& Rabins, 2001; Rosenman et al., 1994; Schulz \& Beach, 1999). There is a strong agreement amongst researchers that caring for persons with chronic illnesses can lead to negative emotional and physical health outcomes for the caregiver (Harris, Thomas, Wicks, Faulkner, \& Hathaway, 2000; Schultz, Newsom, Mittlemark, Burton, Hirsch, \& Jackson, 1997). The current study examines the perceived health status and health promoting behaviors of African American women who are caregivers of persons with ESRD. Little research has been done on this topic and this population despite high prevalence rates of ESRD and its devastating effects on African American populations. Within this chapter, selected published literature describing caregiving research is discussed along with any available research describing the health status and health promotion behaviors of African American women who are caregivers of persons with ESRD.

\section{Caregiver Health Status}

In general, caregiver health status is a growing concern for clinicians and researchers because of the potentially detrimental consequences related to the role of informal caregiver. Several studies conducted over the past four to five decades document detrimental health effects associated with informal caregiving. Many of these studies focused on caregiver burden, stress, and the emotional distress that the caregiver experiences. Historically, many caregiving studies focused on the physical health effects associated with caregiving more often than the health promotion behaviors of caregivers although increasingly the psychological effects of caregiving is being studied. However, published research examining the physical health status of caregivers is more inconsistent in the way that physical health is measured (Schultz, O'Brien, Bookwala, \& Fleissner, 1995; Vitaliano, Schultz, Kiecolt-Glaser, \& Grant, 1997).

Physical health status in caregiving studies is often measured by using a self-rated single item questionnaire, a physical symptoms checklist, or physiological measurements (i.e., body mass index (BMI), blood pressure, lipids levels). Most of the caregiving studies that examined the physical health status of caregivers included White caregivers. Little research has been conducted on the health status of African American caregivers and even fewer studies have examined the health status of African American women who are caregivers. Studies have shown that caregivers of color, when compared with White caregivers, often report worse physical health including self-reported symptoms and perceived health (Pinquart \& Sorensen, 2005). When measuring physical health it is imperative to include both subjective and objective indicators. 


\section{Perceived Health Status}

Most subjective indicators of health status include self-report measures. In the current study the two self-report measures that will be assessed are the caregivers' perceived health status and perceived change in health status since becoming a caregiver. Researchers have found that self-rated health is a strong correlate of objective measures of health and predicts mortality better than either medical records or physician generated data (LaRue, Bank, \& Jarvik, 1979; Mossey \& Shapiro, 1982; Schultz \& Beach, 1999).

Previous studies have documented that family caregivers when compared to noncaregivers are more likely to report that their health is in fair or poor condition (Haley et al., 1999; Haley \& Baley, 1999; Schultz \& Beach, 1999). Burstrom and Fredlund (2001) found that the risk of death was significantly higher among persons reporting poor compared to those reporting good self-rated health. Other studies have concluded that perceived health evaluations are significant predictors or mortality even when physical health status is controlled (Idler, Kasl, \& Lempke, 1990; Kaplan, Barell, \& Lusky, 1988; Mossey \& Shapiro, 1982). Schultz and colleagues (1997) concluded that strained caregivers when compared to non-caregivers reported lower levels of perceived health. African American caregivers when compared to White caregivers reported poorer selfrated health (Haley et al., 1995).

Risky health behaviors of caregivers such as smoking, alcohol use, drug use, and physical inactivity might have effects on both mortality and perceived health status of the caregiver (Idler \& Kas1, 1991). Williams and colleagues (1994) stated that African Americans often disproportionately experience poverty which places them at risk for poorer health outcomes. Therefore, in response to their experiences, their perceptions may be different. Other evaluations of perceived health status include a self-report of change in health status and health behaviors associated with taking on the caregiver role.

\section{Perceived Change in Health Status}

Self-report of change in health status is usually not assessed in behavioral research; however, theories of adaptation and other affective research have documented change in life as a predictor of emotional well-being (Suh, Diener, \& Fujita, 1996; Carver $\&$ Scheier, 1990). It has been documented in caregiving research that the caregiver's well-being may not change based on illness characteristics of the care recipient but rather the caregiver's appraisal of his or her situation and coping capacity (Gitlin, Winter, Dennis, \& Hauck, 2006). Caregivers may experience changes in both physical health and mental health (McConnell, 1994; Pinquart \& Sorensen, 2005; Schultz et al., 1997). Snyder and Keefe (1985) concluded that caregivers report that their health status has declined since providing care to a family member. Similar findings were found in a study conducted by Pratt and colleagues (1985). Bakas and Burgener (2002) conducted a descriptive correlational cross-sectional study using a convenience sample of 104 family caregivers of stroke survivors. The purpose of the above study was to identify predictors of caregiver emotional distress, general health, and stroke-related caregiving outcomes. The researchers concluded that overall, caregivers rated their health as good $(\mathrm{M}=67.3)$; 
however, the caregivers believed that their lives had changed for the worse. Gitlin and colleagues (2006) used the Perceived Change Index (PCI) scale to measure caregiver appraisals of self-improvement or decline in well-being. The sample $(\mathrm{N}=255)$ mainly included women and non-spouses. The mean age of the participants was 61 years of age. The researchers concluded that, in general, caregivers reported more decline in somatic items; however, African American caregivers reported less depressive symptoms, more improvement over time, and appraised caregiving more positively than White caregivers.

\section{DEPRESSIVE SYMPTOMS}

Measurement of depressive symptoms can be one indicator of the caregiver's emotional health status. Depressive symptoms may also influence the way that the caregiver perceives his or her health status. Depressive symptoms and emotional health in general may also determine if the caregiver will participate in health promotion activities or behaviors. There have been many caregiving studies conducted that examined the levels of depressive symptoms amongst caregivers. Schultz (1997) stated that caregivers, when compared to population norms or control groups, report elevated levels of depressive symptoms. Several studies have also found that African American caregivers when compared to White caregivers are less likely to experience depressive symptoms (McConnell \& Gibson, 1997; Sleath et al., 2005).

Sleath and colleagues (2005) examined the relationship between race and psychotropic drug use in informal caregivers of persons with dementia with symptoms of depression. They conducted a national survey using 2,032 African American and Caucasian female caregivers of elderly male veterans diagnosed with Alzheimer's disease or dementia. Depressive symptoms of caregivers were measured using the CES-D. The findings from this study determined of caregivers with depressive symptoms $19 \%$ used antidepressants, $23 \%$ anti-anxiety medications, and 2\% sedatives/hypnotics. The study also determined that African American caregivers were less likely than White caregivers to be taking antidepressants.

There have also been several studies conducted that compared depressive symptoms among ethnically diverse caregivers. Some researchers report no difference in depression between Caucasian and African American caregivers (Cox \& Monk, 1996; Knight, Silverstein, McCallum, \& Fox, 2000), while other studies report that White caregivers are significantly more depressed than African American caregivers (Haley, West, Wadley, Ford, White, \& Barrett, et al., 1995). Haley and colleagues (2004) conducted a multi-site study to compare well-being, appraisal, and religious coping of dementia caregivers by race. The findings from this study were consistent with findings from the above mentioned studies. The researchers determined that African American caregivers reported lower anxiety, better well-being, and used less psychotropic medications than Caucasian American caregivers. Despite the results of this study, the researchers acknowledged that the participants of this study reported more unhealthy behaviors. 
Haley and colleagues stated "This finding is of concern given other indications that African Americans have generally poorer health and access to health care than Caucasians" (p. 325). Dilworth-Anderson and colleagues (2002) suggested that the lack of psychological distress found in African American caregivers may be due to strength of their family resources and religious coping. Despite the evidence to support that caregivers in general report lower levels of health status and more depressive symptoms there is a lack of consensus in the caregiving research findings linking caregiving to poor physical health of caregivers.

\section{OBJECTIVE HEALTH}

Objective health indicators may also influence caregivers' perceived health status. Commonly used indicators of objective health include body mass index (BMI), number and type of prescription medications, and number of recent visits to a health care provider. Studies have shown that caregivers report higher rates of diabetes, arthritis, ulcers, and anemia than the general population (Bakas \& Burgener, 2002; Bakas, Pressler, Johnson, Nauser, \& Shaneyfel, 2006; McConnell, 1994; Pruchno \& Potashnik, 1989). Bernheim \& Korzets, (1999) reported caregivers of individuals on home hemodialysis experience not only emotional stress and depression but worsening physical health. Not only are caregivers at risk for poor physical health they also can be at risk for mortality. Schulz \& Beach (1999) found that strained caregivers with chronic diseases were at risk for mortality. Thirty-three percent ( $\mathrm{n}=392$ caregivers) of these individuals died within 4 years. Research also indicates that female caregivers experience and report more chronic conditions (arthritis, hypertension and heart trouble (Pruchno \& Potashnik, 1989; Zhang, Vitaliano, \& Lin, 2006).

Rosenman and colleagues (1994) conducted an interview survey of 286 women over 50 years of age. Of the 286 women, 191 identified themselves as carers (providing unpaid help, support or supervision to an older frail or disabled person), 110 were caring for a person with a physical disability, and 95 did not have current caring responsibilities. Analysis of the three groups concluded that carers reported more recent symptoms and chronic illness than women who had never experienced caring responsibilities. Some of the most frequently reported symptoms were headaches, tension and nervousness, leg pain, and backache $(\mathrm{p}<0.05)$.

Published research studies indicate that African Americans experience poorer physical health than Whites (Underwood, Buseh, Canales, Powe, Dockery, et al., 2005; United States Department of Health and Human Services, 2004). African Americans when compared to Whites are twice as likely to have diabetes (Hosey, Gordon, \& Levine, 1999). Research also indicates that African American women experience an even greater prevalence of diabetes than do African American men (Hosey, et. al, 1999; Lipton, Liao, Cao, Cooper, \& McGee, 1993). African Americans also experience more complications from diabetes including hypertension (Konen, Summerson, Bell, \& Curtis, 1999), retinopathy (Harris, Sherman, \& Georgopoulos, 1999) and end-stage renal disease (Hosey, et al, 1999). 
There have been several caregiving studies conducted that found a positive relationship between emotional and cardiovascular responses to caregiving (King, Oka, \& Young, 1994; Vitaliano, Schulz, Kiecolt-Glaser, \& Grant, 1997). The majority of the participants in these studies were Caucasian caregivers. Little research has been conducted on the cardiovascular effects of caregiving of African American caregivers even though African Americans experience a higher prevalence rate, earlier onset, and increased severity of hypertension when compared to Caucasian Americans. Picot and colleagues (1997) conducted a study of 18 African American female caregivers and 24 non-caregivers to explore the relationships between caregiver status, demands, resources, socio-demographics, and cardiovascular responses. The findings of this exploratory study showed no significant relationships between caregiver status and daily hassles, age, total chronic conditions, total anti-hypertensives, income, learned resourcefulness, pulse, systolic and diastolic blood pressures among African American females. The researchers stated several possible reasons to explain the lack of significant differences between caregivers and non-caregivers. First, the researchers believed that the participants may perceive caregiver status as a normative daily hassle. Other researchers have also concluded that African American families described caregiving as a normative expectation (Mutran, 1985; Mui, 1992). Second, the lack of significant cardiovascular differences between caregivers and non-caregivers may reflect measurement and design limitations. The blood pressures of the participants were taken at one point in the day. Finally, data were not collected on the duration of caregiving; however, it has been documented that women demonstrate a sustained elevation in cardiovascular responses as early as 3 years after taking on the caregiver role (Markovitz, Matthews, \& Wing, 1991). The researchers concluded that longitudinal studies of the cardiovascular effects of caregiving should be conducted.

Based on the findings from the above mentioned study, Picot and colleagues (1999) conducted a prospective cohort study of 37 caregivers and 38 non-caregivers to determine the relationship between mood symptoms and daytime ambulatory blood pressures during a 12-hour period in African American female caregivers and noncaregivers. Mood symptoms for this study were defined as emotions or feelings that are affected by caregiving stressors in the environment and reflect the state of psychological wellness. The participants recorded their mood symptoms on visual analogue scales to reflect how they felt at the present time. Blood pressure responses were performed with automated portable monitors every 30 minutes during the day. The results of this study revealed no significant difference between mood and blood pressure responses between the two groups; however, the findings indicated that elevated anger was associated with decreases in diastolic blood pressure, while lowered anger was associated with increases in diastolic blood pressure. The researchers suggested that caregivers may have suppressed or denied their anger which lead to the increase in diastolic blood pressure reading.

In contrast, Picot and Genet (1998) found that hypertensive caregivers reported higher levels of caregiving demands and more upsets with the behavior of the care recipients. The researchers conducted this pilot study to explore and compare the levels of caregivers upsets among hypertensive and normotensive African American female 
caregivers. Both the hypertensive and normotensive caregivers reported equal levels of daily hassles, and resources; however, they reported a significant difference in their emotional reactions to the care recipients' behavior. The hypertensive caregivers reported higher levels of caregiving demands and more upsets. Wilcox and colleagues (2005) determined that African American female caregivers experience more hypertension than White female caregivers.

Weight gain is also a common health problem for female caregivers. Research has shown that female caregivers experience a greater increase in weight than control groups (Vitaliano, Zhang, \& Scanlan, 2003). Wilcox and colleagues (2005) determined that African American female caregivers have a significantly higher mean body mass index than White female caregivers $(\mathrm{t}(26)=-2.25, \mathrm{p}=0.03)$. This increase in weight puts caregivers at increased risk for health problems such as, hyperlipidemia, hypertension, diabetes, cardiovascular disease, and arthritis.

Haley and colleagues (1995) conducted a study on the health impact of caregiving on family caregivers of persons with dementia. The researchers used the Cornell Medical Index, a self-report measure of physical health that includes subscales for symptoms in different organ systems (Brodman, Erdmann, Wolff, \& Miskovitz, 1986). The researchers concluded that women reported more symptoms than the male participants.

Research also indicates that caregivers compared to non-caregivers have higher levels of health care utilization as evidenced by both a greater number of prescription medications and a greater number of recent physician visits (Haley, Levine, \& Brown, 1987; Shua-Haim et al., 2001; Zhang et al., 2006). Caregivers compared to noncaregivers experience higher levels of depression and lower levels of life satisfaction (Haley et al., 1987; Shua-Haim, Shi, Kuo, \& Smith, 2001; Zhang et al., 2006). These studies provide important information regarding the mental and physical health of caregivers in relation to non-caregivers. The literature suggests that findings from health effects of caregiving lack consistency. Haley and colleagues (1995) found caregivers did not report more symptoms of poor health than non-caregivers. Cox and Monk (1990) examined the health of 31 African American and 19 Hispanic caregivers in New York and Baltimore. The researchers used a survey to assess the caregiver's physical health. The researchers concluded that no significant differences in caregiver's health background characteristics, including the number of annual doctor visits, self-rated physical health, or self-reported changes in medical conditions or overall health existed between the two groups. In contrast, Shultz and colleagues (1997) concluded that strained caregivers rated their health as lower and used more prescription medications compared to non-strained caregivers and non-caregivers. There are a few explanations of these conflicting findings. First, physiological health responses to caregiving are difficult to measure. It is possible that these responses would not be detectable for long periods of time. Second, it is possible that different measure of objective health were used to assess objective health status. Third, many caregiving studies include convenience samples including highly distressed caregivers (Pinquart \& Sorensen, 2003). Fourth, it is possible that caregivers have adjusted to the caregiving role and they have not experienced a change in their health status (Given \& Given, 1998). Finally, most reported studies on 
health effects of caregiving included large samples of White participants or small numbers of caregivers from other ethnic groups (Pinquart \& Sorensen, 2005). It is imperative that health care providers systematically examine the health status of African American women who are caregivers as caregiver health studies seldom include these women.

\section{DEMOGRAPHIC FACTORS}

Research conducted across a variety of chronic illness populations has shown that there are many factors associated with the negative effects of caregiving. Age, income status, level of education, marital status, and length of caregiving are independent and significant correlates that can negatively affect the health status of informal caregivers, particularly in older caregivers (McDonald, Brennan, \& Wykle, 2005; Schultz \& Beach, 1999; Schulz \& Beach, 1999).

Wykle and Segall (1991) compared 20 African American and 20 White family caregivers of family members with dementia to examine racial differences in caregiver stress, coping, and health. It was found that African American caregivers were more likely to be unmarried and reported lower incomes than White caregivers. Hinrichenen and Ramirez (1992) examined 33 African American and 119 White caregivers of persons with dementia to determine if there were racial differences in the social and family context of caregiving, patterns of adaptation to caregiving, and the utilization of support services existed. The researchers determined that African American caregivers when compared to Caucasian caregivers were less likely to be married, younger, and not a spouse of the care recipient.

Lawton, Rajagopal, Brody, and Kleban (1992) found that African American caregivers were more likely to be older, female, widowed and reported lower incomes and educational attainment. Macera and colleagues (1992) conducted a study with 20 African American and 62 White caregivers of persons with Alzheimer's disease to examine racial differences in perceived burden. The researchers found that demographic characteristics of their study were comparable to those in the aforementioned studies. The study determined that African American caregivers were less likely to be a spouse and to report lower incomes than the White caregivers. These results are similar to those found by Sorensen and Pinquart (2005).

Similar findings were reported by Cox (1993) who conducted a study to assess caregiver's use of services offered by the Alzheimer's Association in Baltimore, Maryland and Washington, D.C. Cox interviewed 76 African American and 88 White dementia caregivers to assess relationship strain, social activity restriction, depressive symptoms, caregiving competence, patient functioning and disruptive behavior, the availability of informal support, filial expectations of support, and the utilization of formal services. The findings from this study suggest that African American caregivers when compared to White caregivers were less likely to be the spouse of the care recipient and reported lower levels of income. 
Haley et al. (1995) completed a comparative study of 70 African American and 105 White caregivers of persons with dementia and 70 African American and 105 White non-caregivers to compare psychological, social, and health variables. Haley and colleagues determined that African American caregivers when compared to White caregivers were less likely to be married, younger, reported lower family socioeconomic status, and had completed less years of education.

Miller, Campbell, Farran, Kaufman, and Davis (1995) conducted a study of 77 African American and 148 White spouse caregivers of persons with dementia to examine relationships between race, sense of control, caregiver mastery, caregiver depression, and role strain. The researchers determined that African American caregivers when compared to White caregivers were younger and reported lower levels of income. Bullock and colleagues (2003) conducted a descriptive study with 119 African American elder caregivers to examine the extent to which caregivers' employment statuses affect the hours of care provided. The researchers compared employed caregivers $(52 \%)$ to unemployed caregivers (48\%). In contrast to other caregiving studies, the majority of the caregivers were women. The researchers concluded that employed caregivers tend to be younger and healthier than unemployed caregivers and were more likely to be a child of the care recipient. The amount of care provided by the primary caregiver did not vary based on employment versus unemployment status. The researchers also concluded that some caregivers experienced a loss of wages due to their roles as caregiver and employee.

In summary, several differences between African American and White caregivers were consistently reported. When comparing African American caregivers to White caregivers, African American caregivers are less likely to be a spouse (Cox, 1993, 1995, Haley, 1995; Lawton et al., 1992; Hinrichenson \& Ramirez, 1992; Macera et al., 1992). African American caregivers are more likely to be an adult child, friend, or other family member (McConnell \& Gibson, 1997). African American caregivers are less likely to be married (Haley, 1995; Lawton et al., 1992; Wykle \& Segall, 1991), less educated (Haley, 1995 and Lawton et al., 1992) and report lower levels of incomes (Cox, 1993, 1995; Haley, 1995; Lawton et al., 1992, Macera et al., 1992) than White caregivers.

\section{CAREGIVER AGE AND PERCEIVED HEALTH STATUS}

Studies have shown that age may or may not be affect the health status of the caregiver. Developmentally older adult caregivers compared to younger adult caregivers may expect to assume the role of caregiver as chronic illness and disability are often expected consequences of aging (Brody, 1985). It has also been reported that as many as $60 \%$ of older adults attribute health conditions and disability to the normal process of aging (Sarkisian, Liu, Ensrud et al., 2001; Gump, Matthews, Scheier, et al., 2001). Little caregiving research specifically addresses young caregivers. Younger adult caregivers often have multiple competing roles that include parenting, head of household, employee, and possible caregiver to multiple persons (Levine, Hunt, Halper, Hart, Lautz, \& Gould, 2005). There are several research studies that document the relationship between caregiver age and burden and strain (Cain \& Wicks, 2000; Cox, 1995); however, fewer 
studies have been done to examine the relationship between age and perceived health status of caregivers. In the next section the correlates of age and perceived health status will be discussed.

Harwood and colleagues (2000) examined factors associated with perceived health status of 64 White family caregivers of community dwelling Alzheimer's disease patients. The researchers concluded that poor self-rated health was predicted by older caregiver age and greater depressive symptoms reported by the caregiver. The caregiver's mean age was $79.0(\mathrm{SD}=5.9)$ years, with ages ranging from 67-91. Older caregivers in this study reported worse self-rated health. This finding has also been reported in prior research among persons caring for patients with dementia (Haley, Levine, Brown, \& Bartolucci, 1987). Fifty-two percent of the participants were female. Self-rated health was measured using the 5-item general health perceptions scale of the Medical Outcomes Study 36-item Short-Form Health Survey (SF-36) (Ware, 1993).

In the general population, older adults may develop certain disabling medical conditions including hypertension, heart disease, hearing and visual impairments, and orthopedic impairments Shifren (2001) and Shifren and Kachorek (2003) studied 24 participants aged 21 to 58 years who had been caregivers while under the age of 21 . The researchers found caregivers reported more positive than negative mental health; however, $42 \%$ reported high depressive scores.

Several caregiving research studies report no significant differences in the association between age and caregiver outcomes between African American and White caregivers (Cox, 1995; Mui, 1992). However, Reed (1990) suggests that African Americans, in general, age 65 and older have higher rates of functional disabilities and health problems and under-use medical care services. Thus, due to the higher rates of functional disabilities and health problems, older African American caregivers may experience lower perceived health.

\section{DEMOGRAPHIC FACTORS AND OBJECTIVE AND SUBJECTIVE HEALTH FACTORS AND PERCEIVED HEALTH STATUS}

Results of several studies have shown that socio-demographic factors are often independently related to health outcomes. The literature reveals that caregivers with lower education and income levels experience poorer health outcomes compared caregivers with better resources (Dilworth-Anderson, Goodwin, \& Williams, 2004; Schultz et al., 1997; Sorensen \& Pinquart, 2005). African American caregivers are often employed and unable to alter their work schedules (Neal, Chapman, \& Ingersoll-Dayton, 1993).

Dilworth-Anderson, Goodwin, and Williams (2004) examined the health outcomes and the role of culture in predicting health outcomes of 107 African American caregivers who provided care to elderly dependent family members. Using the stress and coping model of Pearlin and colleagues (1990) they analyzed the direct effects of background characteristics and stressors and the direct and mediating effects of resources 
on the caregiver's psychosocial health and physical functioning by using hierarchical multiple regression analyses. The results of the study were similar to finding from others studies. The study determined that combinations for caregiver background characteristics, stressors, and resources had direct effects on African American caregivers' health outcomes. The results of the study also revealed that cultural beliefs and values of African American caregivers help explain health outcomes.

Bakas and Burgener (2002) conducted a descriptive correlational cross-sectional study using a convenience sample of 104 family caregivers of stroke survivors to examine predictors of emotional distress, general health, and stroke-related caregiving outcomes. Analysis of the data revealed that $61 \%$ of all the caregivers who did not live with the care recipient's were employed. The analysis of data also revealed that predictors of poorer health $\left(\mathrm{R}^{2}=.48, \mathrm{p}<.001\right)$ were not living with the patient and low household income.

Harwood and colleagues (2000) conducted a product-moment correlation analyses to examine the bivariate associations between self-rated health and independent variables including caregiver age, psychological factors (depressive symptoms, appraised burden, appraised satisfaction, perceived social support); and patient clinical factors (symptoms of behavioral pathology, severity of the dementing illness). The researchers determined that $41 \%(n=26)$ of the caregivers reported significant symptoms of depression (CES-D $>16)$. The results of the correlational analyses revealed that self-rated health was positively correlated with appraised burden $(\mathrm{r}=.40, \mathrm{p}<.01)$ and social support $(\mathrm{r}=.35, \mathrm{p}$ $<.001)$, and negatively correlated with depressive symptoms $(\mathrm{r}=-.62, \mathrm{p}<.01)$ and age $(\mathrm{r}=-.54, \mathrm{p}<.01)$. The researchers conducted a multiple regression analysis which showed that self-rated health was associated with greater caregiver depression and older age. The largest variance was accounted for by the level of depressive symptoms (.39) and then by older age (.11). The findings of this study did not reveal that patient clinical factors influence caregivers' self-rated health. The findings from this study were supported by findings from studies conducted among dementia family caregivers (Lawton et al., 1991; Prunchno et al., 1995) which showed that family caregivers who were clinically depressed reported declines in their physical health status.

\section{CAREGIVER'S HEALTH PROMOTION BEHAVIORS}

Risky health behaviors of caregivers such as smoking, alcohol use, drug use, physical inactivity might have negative effects on both mortality and perceived health status of the caregivers (Idler \& Kasl, 1991). Several studies have examined the health of caregivers (Schulz \& Beach, 1999; Haley, et al., 2004); however, fewer published studies exist on the health promotion behaviors of caregivers. It is imperative that the health of the caregiver be maintained in order for caregivers to continue their role as caregiver. McKinlay and colleagues (1995) reported that nursing home placement or institutionalization of the older adult was twice as likely to occur when the caregivers experienced negative impacts on sleep, health, leisure time, and management of household chores. 
Connell (1994) who conducted a retrospective data analysis of 44 family caregivers found that one third of the participants reported that they ate less nutritiously, exercised less, and used more medications to promote sleep. Similar findings were reported by Acton (2002) who compared health-promoting self-care behaviors in 46 family caregivers to 50 demographically matched non-caregivers. The researcher concluded that family caregivers scored significantly lower on Importance of Self-Care, Health Responsibility, Physical Activity, Spiritual Growth, Interpersonal Relationships, Stress Management, Total Health-Promotion Actions, and Hours of Sleep $(p<0.01)$. In support of the reported finding above, Burton and colleagues (1997) compared preventive health behaviors in 434 spouse caregivers to 385 demographically matched noncaregivers. The researchers concluded that caring for a spouse with activity-of-daily living impairments significantly increased the risk for not getting enough rest, not having enough time to exercise, not being able to take enough time to recuperate from illness, and forgetting to take prescription medications.

McConnell (1994) also reported that the role of caregiver interfered with conducting health promotion behaviors. The researcher concluded that over one-third of the caregivers $(n=44,39 \%)$, reported that they ate less nutritiously since becoming a caregiver and 14 percent reported that their appetite has declined. The researcher also found that almost one-half of the caregivers who smoke (43\%) report increasing the number of cigarettes smoked per day since becoming a caregiver. Forty percent of the participants reported that their physical health had been negatively affected by caring for their spouse.

Burton and colleagues (1997) conducted a secondary data analysis using a sample of more than 3,000 married, community-dwelling older persons, who were enrolled in a large Cardiovascular Health Study. The purpose of the study was to explore the relationship between caregiving and lifestyle health behaviors and use of preventive services. Each participant was categorized into level of caregiver based on the level of caregiving need. High-level caregivers were defined as having a spouse with an activity of daily living impairment $(\mathrm{n}=212)$ and moderate-level caregivers were defined as having a spouse with one or more instrumental activities of daily living $(n=222)$. For each caregiver, a control using matched age and gender was selected $(n=385)$. The researchers concluded that high-level caregivers when compared to non-caregivers, did not get enough rest, did not participate in exercise regularly, did not have enough time to rest or recuperate from illness, and often forgot to take prescription medication $(p<.000)$.

Even though there are several published studies documenting the health promotion behaviors of caregivers there are fewer published studies that document the health promoting behaviors of African American caregivers (McDonald, Brennan, \& Wykle, 2005; McDonald, Fink, \& Wykle, 1999; McDonald \& Wykle, 2003). McDonald and Wykle (2003) conducted a secondary data analysis of 66 African American and 110 White caregivers of impaired older adults to examine predictors of health-promoting behavior. The researchers concluded that the number of health-promoting behaviors was significantly different between African American and White caregivers, with White caregivers reporting a higher number of health promoting behaviors $(p<0.05)$. In support 
of the reported finding above, McDonald, Brennan, and Wykle (2005) found African American caregivers reported a significantly lower number of health-promoting behaviors than did White caregivers ( $\mathrm{t}$-value $=2.81, \mathrm{df}=393, \mathrm{p}<0.05$ ). Lower percentages of African Americans caregivers reported getting adequate sleep, eating breakfast, not smoking, and exercising when compared to White caregivers. This study also documented that African American female caregivers reported that they were overweight and that they exercised less than the participants in the other three groups (African American male, White male, White female).

\section{SUMMARY OF THE REVIEW OF LITERATURE}

Little research has been done to explore the health status of African American women caregivers and fewer studies have been conducted on African American women who are caregivers of persons with ESRD. There is a strong agreement amongst researchers that caring for persons with chronic illnesses can lead to negative emotional and physical health outcomes for the caregiver (Harris, Thomas, Wicks, Faulkner, \& Hathaway, 2000; Schultz, Newsom, Mittlemark, Burton, Hirsch, \& Jackson, 1997). Caregivers may experience changes in both physical health and mental health upon assuming the caregiver role (McConnell, 1994; Pinquart \& Sorensen, 2005; Schultz et al., 1997). Research indicates that on average caregivers rate their health as good; however, there are some caregivers who rate their health as fair or poor. Research also indicates that African American caregivers may have lower levels of depressive symptoms when compared to Caucasian caregivers. Research also indicates that caregivers compared to non-caregivers have higher levels of health care utilization as evidenced by both a greater number of prescription medications and a greater number of recent physician visits. African American caregivers are more likely to be an adult child, friend, or other family member (McConnell \& Gibson, 1997). African American caregivers are less likely to be married (Haley, 1995; Lawton et al., 1992; Wykle \& Segall, 1991), less educated (Haley, 1995 and Lawton et al., 1992) and report lower income levels (Cox, 1993, 1995; Haley, 1995; Lawton et al., 1992, Macera et al., 1992) than Caucasian caregivers. Research documents that African American caregivers often do not practice health promotion behaviors. 


\section{CHAPTER 3. METHODOLOGY}

This chapter addresses the methodology used to answer the research questions in the current study. The paragraphs that follow describe the research design, sample and setting, instruments, procedures, and strategies used to protect human subjects.

\section{RESEARCH DESIGN}

The design for this study was a cross-sectional, descriptive correlational secondary analysis of data obtained from 75 African American women caring for a relative diagnosed with ESRD. These women participated in a larger study designed to investigate the predictors of health and burden in 120 family caregivers of patients with ESRD. The cross-sectional design was used in the current study because of the descriptive nature of the study aims. The focus of the study was not on the caregiver experiences over time. The correlation design was used to examine the relationship of the independent variables (age, education, marital status, income, etc.) on the outcome or dependent variable, which was perceived health status.

\section{Sample and Setting}

The study included 75 African American women who were caregivers of a relative (i.e., family member) diagnosed with ESRD and receiving chronic dialysis therapy. The original convenience sample was recruited from three private, physicianowned dialysis centers located in a large metropolitan city located in the southeastern United States. Males, whites, and program participants with incomplete data were excluded from this secondary data analysis because of the desire to describe the health status of this understudied population of African American women.

\section{Inclusion Criteria}

The participants for this study were African American women who were caregivers of persons with ESRD and members of the previously described primary study. Criteria for inclusion for this study included:

- a primary family caregiver of patients with ESRD receiving in-center hemodialysis, home hemodialysis, or home peritoneal dialysis. Primary caregivers are those individuals whom the care-recipient reported cared for them or would care for them if they could no longer care for themselves.

- an African American woman who was caring for a relative with ESRD who was receiving dialysis treatment from one of the three study sites.

- age 18 years or older at the time of enrollment in the original study. 
- gave verbal and signed consent to participate in the larger study of caregivers of person with ESRD.

- able to read and speak English.

\section{Exclusion Criteria}

Participants that were excluded from the current study were:

- unable to speak or read English because all study instruments required participants to have the ability to read English. Several of the study instruments have not been validated in those individuals who speak English as a secondary language.

- caregivers of dialysis recipients who were not African American.

- caregivers of dialysis recipients who were male.

- caregivers of dialysis recipients who had a non-functioning kidney transplant at the time of caregiver enrollment.

- caregivers of patients diagnosed with ESRD but who were not receiving dialysis

- caregivers of dialysis recipients with acute reversible renal failure.

\section{INSTRUMENTS}

In the initial data collection process, questionnaires were completed independently by participants after receiving verbal instructions from the researcher. The current study involved a secondary data analysis of data collected using the following instruments: The Caregiver Demographic Data Form, Caregiver's Perceived Health Form, Severity of Caregiver's Disease Scale, and the Center for Epidemiological Studies Depression Scale (CES-D). Each instrument is described.

\section{The Caregiver Demographic Data Form}

The Caregiver Demographic Data Form (see Appendix A), a self-administered questionnaire, provides characteristics of the family caregiver and patient diagnosed with ESRD. This form is an open-ended response form that was developed by the principal investigator in the larger study designed to investigate the predictors of health and burden in 120 family caregivers of patients with ESRD. This instrument is written at a $6^{\text {th }}$ grade reading level.

Demographic variables included in the questionnaire were: caregiver's age, gender, race, marital status, education, income, and relationship to the patient. Family caregivers also provided data about the patients' characteristics. The demographic variables were analyzed using descriptive statistics. Estimated time to complete the demographic items was no more than 5 minutes (Harris, 2000). 


\section{Caregivers' Perceived Health Form}

Self-rated health was measured with the Caregivers' Perceived Health Form (see Appendix B). This form is a single-item, self-rated health question that was used to evaluate the caregivers' perception of their own health. Response categories for the selfadministered scale range from 1 (excellent) to 5 (poor) with higher scores reflecting poorer health status. Other researchers have shown that lower self-rated health was a good indicator and correlate of morbidity and mortality (Idler \& Benyamini, 1997). Schultz and Beach (1999) also found that caregivers who had a lower self-rated health were at a higher risk of mortality compared to non-caregivers. This questionnaire is related to the instrument used by Schultz (1994) in the Caregiver Health Effects Study therefore supporting the construct validity of this item. The self-rated health questionnaire took less than 1 minute to complete in the initial study (Harris, 2000).

\section{Severity of Caregiver's Disease Scale}

In the initial study, caregiver's objective health was measured using the Severity of Caregiver's Disease Scale (Phillips \& Rempusheski, 1986). The multi-item scale measures caregiver health status in three ways. A modified instrument has been included in Appendix C. The first questionnaire assesses current and past problems that may interfere with the caregiver's daily activities. In this study, the first way the caregiver's objective health status was measured was by a self-report of height (in inches) and weight (in pounds) in order to calculate the caregiver's BMI. The number and type of health problems were also self-reported. The health problems are listed by organ systems in the body, such as, cardiovascular, respiratory, urinary, gastrointestinal, and endocrine. On a separate page, a general review of health problems was listed under each system so that caregivers understood which health problems were categorized with each body system. For example, the cardiovascular category includes chest pain, hypertension, anemia, pacemaker, irregular heartbeat, etc. Caregivers were then asked to indicate the degree (severity) to which each problem stood in the way of them doing what they wanted. The responses included extremely (5), very (4), moderately (3), somewhat (2), not at all (1), and not applicable $(0)$. Health problems were scored by summing severity ratings. The total score can range from 0 - 64. Higher scores indicate poorer health. An alpha coefficient of .81 was found in caregivers of elderly patients (Phillips \& Rempusheski, 1986), thus establishing internal consistency of the instrument. Cronbach's alpha coefficients in Hispanic and Anglo caregivers of elderly patients were .84 and .78, respectively (Phillips \& Rempusheski, 1986). The Severity of Caregiver's Disease Scale $(\mathrm{r}=.81)$ is strongly correlated with the Health Perception Questionnaire (Ware \& Karmos, 1976) and the Exercise of Self-care Agency Scale (.91) (Kearney \& Fleishcher, 1979) thus supporting the construct and content validity of the instrument. In the initial study (Harris et al., 2003), the individual organ system ratings were significantly correlated with the Caregiver Perceived Health Form, thus establishing construct validity of these instruments in the study sample.

The second way caregiver's objective health status was measured was in relation to how the caregiver's health changed since becoming a caregiver. The 16-item 
instrument is comprised of health related habits in which the caregiver may be involved. The responses are coded to include five categories: no change, some change, moderate change, great change, and don't do. The caregivers in the original study from which data for the current study were derived were given written instructions to mark the extent of the change with health related habits and then rate whether the type of change was good or $b a d$. The responses were coded to reflect the five categories previously mentioned.

The third way caregiver objective health status was assessed was by caregiver recall. These include (a) caregiver's height and weight were used to calculate body mass index (BMI) using the Center for Disease Control formula, which is weight in kilograms divided by square of height in meters, (b) number and type of prescribed medications taken by the caregiver, and (c) number of visits to the doctor's office within the last 6 months. The caregivers from the larger sample were then asked, "What do you do for yourself to stay healthy?" Caregiver recall of medications and doctor's office visits were analyzed using descriptive statistics (i.e., means, standard deviations, and ranges). These caregiver responses were the only data used as caregiver characteristics from the Severity of Caregiver's Disease Scale. Also, the number of doctor visits and prescribed medications were highly correlated with the single-item, self-rated health question supporting the construct validity of the item.

\section{Center for Epidemiological Studies Depression Scale}

The Center for Epidemiologic Studies (CES-D) Depression Scale (see Appendix D) was used in this study to measure caregivers' level of depressive symptoms. The CESD (Radloff, 1977) was developed by the Center for Epidemiological Studies to measure depressive symptoms in the general population. The 20-item self-reported scale assesses the dimensions of depressed mood, feelings of guilt, appetite loss, sleep disturbance, and energy level during the past week. Response categories of the CES-D range from rarely or none of the time to most or all of the time, and scored 0-3 with higher scores reflecting more frequent depressive symptoms. Questions 4, 8, 12, and 16 are reversed scored and worded positively to discourage a response set. The total score of the CES-D is the sum of all item responses and can range from 0 to 60 (Radloff, 1977). Scores of $0-15$ are generally interpreted to indicate no depressive symptoms, 16 - 20 mild distress, 21 - 30 moderate distress, and 31 and over severe distress (Zich, Atkisson, \& Greenfield, 1990).

The CESD-D has been used in many studies of caregivers of patients diagnosed with Alzheimer's disease and cancer and caregivers of geriatric patients (Ensel 1986, Zich, Atkisson et al. 1990). The CES-D has been validated against other self-report measures and clinical diagnoses. It has a high internal consistency and good test-retest reliability (Ensel, 1986). The instrument was developed from five validated depression scales including the Beck Depression Inventory (BDI). The CES-D has been used in studies of caregivers of patients with a mental illness and daughter caregivers of patients with cancer and the reliability in these studies was .90 and .91 (Raveis, Karus, \& Siegel, 1998; Song, Biegel, \& Milligan, 1997). 
Radloff (1977) reported that the CES-D is suitable for use in black and white English-speaking American populations of both sexes. Radloff also stated that this instrument can be used in studies of persons of diverse socioeconomic statuses and age ranges. The CES-D has been used in several studies that include African American caregivers (Harris et al., 2000; Wicks et al., 1997). The CES-D was chosen because it has been found to be a valid and reliable measure of depressive symptoms in African American caregiver populations. Which facilitates comparing findings from the current study with findings from published studies.

\section{Procedure}

Permission to conduct the proposed study was obtained from the University's Institutional Review Board (IRB). The dialysis centers' owners/medical directors previously gave written and verbal approval to recruit the caregivers for the larger study. The caregivers from the initial study (Harris, 2000) gave written and verbal informed consent. Letters of approval from the IRB are provided in Appendix E.

\section{Site Preparation}

In the initial study, Harris (2000) prepared a letter for the patients and their caregivers. This letter was presented to the dialysis centers' owner/medical director 3-4 weeks prior to data collection. The letter included the purpose of the study and explained to the caregivers and patients that their treatment would not change if they did or did not participate in the study. Institutional Review Board (IRB) approved pamphlets that included Harris' and her research assistant's pictures and a written description of the purpose of the study were also distributed in each of the sites. Harris also prepared the dialysis centers' registered nurses 2 weeks prior to data collection by educating them on the purpose of the study and on caregiver burden and caregiver health in caregivers of persons with ESRD.

\section{Selection of Participants}

The participants in this study were selected based on the information provided in the larger study of caregivers of persons with ESRD (Harris, 2000). The patients in the dialysis centers, were asked "if you become unable to care for yourself who would you ask to take care of you?" to identify their primary caregiver. The principal investigator (PI) in the current study was given de-identified data that had a subject number and no personal identifiers. The data set did not include the participant's birthdates, social security numbers, or any other type of personal identification that could tie specific participants to the dataset information. The PI was not allowed to view the consent forms from the larger study. The study sample for the current study included 75 African American female caregivers who did not have significant missing data on the relevant study questionnaires. The data collection for the larger study occurred at three dialysis centers in a southeastern metropolitan area. Permission to conduct the initial study and 
the secondary data analysis was obtained from the University's Institutional Review Board (IRB).

\section{Data Analysis}

The data that were used for the current study were maintained on a Microsoft Excel spread sheet. The data were analyzed using Statistical Package for the Social Sciences 15.0 (SPSS) computer software. The statistical analyses used for this study are described in the following paragraphs. Statistical analysis for this study included descriptive statistics (i.e., mean, median, mode, standard deviation, range), the appropriate parametric and nonparametric tests, bivariate correlational analyses, and multiple regression analysis. The level of significance was set at .05 for each research question. The level of significance for bivariate correlational analyses conducted to identify predictor variables used in the regression model was set at .20.

\section{STATISTICAL ANALYSES OF SAMPLE DEMOGRAPHIC INFORMATION}

Initially descriptive statistics were completed to determine the sample demographic information. Measures of central tendency (i.e., mean and median), variability (i.e., range and standard deviation), and frequency distributions (i.e., symmetrical and asymmetrical) were performed by using the SPSS computer software. Caregiver demographic information that was analyzed included: age, marital status, income, hours of care provided, number of months of care provided, and relationship to patient. Data about the patient's age, gender, length of illness, and living arrangements were also analyzed. These independent variables were coded as either continuous or categorical data.

\section{Research Question One}

Research Question One asked what the level of perceived health status was reported by African American women who are family caregivers of persons with ESRD, which we determined by asking the following questions.

a. What is the perceived health status reported by African American women who are family caregivers of persons with ESRD?

b. What is the perceived change in health status since the caregiving role began as reported by African American women who are family caregivers of persons with ESRD?

c. What is the level of depressive symptoms reported by African American women who are family caregivers of persons with ESRD?

Descriptive statistics was performed prior to answering questions 1(a), 1(b), and 1(c). This statistical procedure provided the researcher with information such as the 
mean, median, frequency tables, and whether data were normally distributed. Descriptive statistics were reported in order to answer these research questions.

\section{Research Question Two}

Research Question Two asked what the objective health factors (BMI, number of prescription medications, number of physician office visits, and number of health problems) and the relationship between objective health factors and age of African American women who are family caregivers of persons with ESRD, which we determined by asking the following questions.

Research Question Two asked what objective health factors were reported by African American women who are family caregivers of persons with ESRD, and what relationship existed between objective health factors and age, which we determined by asking the following questions.

a. What is the body mass index (BMI) and the association between BMI and age of African American women who are family caregivers of persons with ESRD?

b. What is the number of prescription medications and association between number of prescription medications and age of African American women who are family caregivers of persons with ESRD?

c. What is the number of physician office visits and the association between number of visits to a health care provider and age of African American women who are family caregivers of persons with ESRD?

d. What is the number of health problems and the association between number of health problems and age of African American women who are family caregivers of persons with ESRD?

Research questions 2(a), 2(b), and 2(c) were answered using Spearmans correlational analysis. The correlational analyses were computed to examine the interrelationship among the study variables. Due to the small sample size, descriptive statistics were not performed on each age category. The research questions were revised to examine the relationship between BMI and caregiver age, number of reported health problems and caregiver age, number of prescription medications and caregiver age, and number of physician office visits in the past 6 months and caregiver age. Prior to computing correlational analysis graphic plotting of the relationship between the independent variable (caregiver age) and dependent variables (BMI, number of health problems, number of prescription medications, and number of visits to health care provider) was performed to allow for a visual representation of variable relationships and to determine if these relationships were linear. Data that did not demonstrate a linear relationship were analyzed using Spearman's correlational coefficient analysis (Burns \& Grove, 2005). 


\section{Research Question Three}

Research Question Three asked what relationship existed between the perceived health status and age of African American women who are family caregivers of persons with ESRD.

Research question 3 was answered using Spearman's coefficient correlational analysis. Correlation analyses were computed to determine the interrelationships among the study variables. To determine if this relationship between the two variables was linear, graphic plotting was performed to provide a visual examination of the variable relationships. Data that were not considered normal (i.e., right skewed), were analyzed by using the Spearman's correlational coefficient. The relationship between the independent variable (age) and dependent variable (perceived health status) was examined using Spearman's correlational coefficient analysis.

\section{Research Question Four}

Research Question Four asked what demographic factors (age, level of education, and socioeconomic status) and objective and subjective health factors that predicted perceived health status as reported by African American women who are family caregivers of persons with ESRD.

Research question 4 was answered by using a multiple regression analyses to determine which variables predicted the perceived health status of African American women who were family caregivers of persons with ESRD. A stepwise multiple regression analysis was performed to determine which independent variables best predict the dependent variable. Prior to regression analysis, correlation analyses were performed to determine the possible predictor variables for inclusion in the regression analysis. The demographic factors and objective and subjective health factors with significant linear relationships with the dependent variable were entered into the multiple regression analyses to determine which variables predicted the dependent variable. Next, stepwise multiple regression analysis was performed to determine the amount of the variation of perceived health status scores was explained by each predictor variable and the significance of the relationship of the predictor variable with the dependent variable. The degree of the linear relationship between independent and dependent variables was used to determine which variables were entered into the regression model. A weak linear relationship is considered if $\mathrm{r}$ is .10 to .30 , a moderate linear relationship is considered if $\mathrm{r}$ is .30 to .50 , a strong linear relationship exists if $\mathrm{r}$ is .50 or above. The conceptual framework, previous caregiving research studies, and significant correlations were used to determine which independent variables would be considered for entry into the regression analysis. 


\section{Research Question Five}

Research Question Five asked what number and types of health promotion behaviors were reported by African American women who are family caregivers of persons with ESRD.

Descriptive statistics were performed prior to answering question 5. This statistical procedure provided the researcher with information such as the mean, median, frequency tables, and whether data were normally distributed. Descriptive statistics were reported to answer this research question.

\section{Protection of Human Participants}

The current study and the initial study received approval from the University's Institutional Review Board (IRB). The dialysis' centers owners/medical directors also gave written and verbal approval to recruit caregivers at the dialysis centers. The participants in the initial study (Harris, 2000) also gave written and verbal informed consent. Appropriate guidelines were followed to maintain anonymity and confidentiality for the participants. The privacy of the participants in the current study was maintained due to the fact that the PI received de-identified data from the larger study. The PI was unable to identify the participants based on their responses. The instruments used in the initial study posed minimal risk for participants. The participants from the larger study were at risk for emotional distress associated with items included in the study instruments and recollections of the caregiving experience. The potential risks of the initial study were outweighed by the potential benefit of this study since findings could help to identify significant predictors of caregiver outcomes. Since this study was a secondary data analysis, there were no physical, social, or legal risks involved in the current study and none were reported in the primary study (Harris, 2000). 


\section{CHAPTER 4. RESULTS}

The purposes of the present study of African American women who were family caregivers of persons with ESRD were to 1) identify their perceived health status, changes in perceived health status since assuming the caregiver role, and level of depressive symptoms; (2) document objective health factors and the association between objective health factors and age; (3) document the relationship between age and perceived health status; (4) identify demographic and subjective and objective health factors that predict perceived health status; and (5) identify their health promotion behaviors. The mean scores for study variables are described. Finally, the results of each research question are discussed.

\section{DEMOGRAPHIC CHARACTERISTICS}

\section{End Stage Renal Disease Caregiver Profile}

A summary of caregivers' characteristics is shown in Table 1. The mean age of the caregivers was 47 years and average education level was 13 years. Many of these caregivers were young to middle-aged adults. They were employed on average 23 hours per week and provided 27 hours of caregiving, thus for many caregivers the hours spent in caregiving was equivalent to a part-time job.

\section{End Stage Renal Disease Patient Profile}

Descriptive statistics for patients are provided in Table 2. Patients ranged in age from 21 to 90 years, with a mean age of 57.5 years. Patients were equally represented by both genders (53.3\% male, $46.7 \%$ female). The majority of the patients and caregivers lived in the same residence $(62.7 \%)$.

\section{RESEARCH FINDINGS}

\section{Specific Aim One}

Specific Aim One was to identify the level of perceived health status reported by of African American women who are family caregivers of persons with ESRD.

Descriptive statistics were performed to answer questions 1(a), 1(b), and 1(c), which focused on perceived health status, changes in health status, and level of 
Table 1. Demographic Characteristics of African American Women Who Are Caregivers of a Relative with End Stage Renal Disease ( $\mathrm{N}=75)$.

\begin{tabular}{lcc}
\hline Characteristics & $\mathrm{M} \pm \mathrm{SD}$ & $\mathrm{n}(\%)$ \\
\hline Age (years) & $46.93 \pm 13.8$ & 75 \\
Months of Care & $49.13 \pm 55.38$ & 75 \\
Body Mass Index (BMI percentage) & $31.29 \pm 7.08$ & 75 \\
Education (years) & $13.09 \pm 2.6$ & 74 \\
Annual Income & $23317.53 \pm 18492$ & $55(41.25)$ \\
Hours of care (per week) & $27.03 \pm 27.28$ & 74 \\
Marital Status & & \\
Married & & $31(41.3)$ \\
Single & & $29(38.7)$ \\
Divorced & & $10(13.3)$ \\
Separated & $1(1.3)$ \\
Widowed & $4(5.3)$ \\
Relationship & & \\
Wife & & $24(32)$ \\
Daughter & & $7(9.3)$ \\
Parent & & $11(14.7)$ \\
Sibling & & \\
Other & &
\end{tabular}

Note: $\mathrm{N} \neq 75$ due to missing data. 
Table 2. Demographic Characteristics of Patients with End Stage Renal Disease $(\mathrm{N}=75)$.

\begin{tabular}{lcc}
\hline Characteristics & $\mathrm{M}+\mathrm{SD}$ & $\mathrm{n}(\%)$ \\
\hline Age (years) & $57.53+15.4$ & \\
Length of illness (months) & $32.5+33.6$ & \\
Gender & & \\
$\quad$ Male & $40(53.3)$ \\
$\quad$ Female & $35(46.7)$ \\
Reside with caregiver & $47(62.7)$ \\
\hline
\end{tabular}

Note: $\mathrm{N} \neq 75$ due to missing data. 
depressive symptoms. This statistical procedure provided the researcher with information such as the mean, median, frequency, and whether data were normally distributed. A summary of the results of the descriptive statistics procedures as shown in Table 3 indicated that on average $29(38.7 \%)$ participants rated their health as good. However, $28 \%$ rated their health as either fair or poor.

Caregivers were also asked to identify changes in their health status in predetermined areas, the degree of change (e.g. some, moderate or great change), and whether the change was good or bad (research question 1b). Caregivers reported several negative changes in health associated with the caregiving experience. The most frequently reported bad changes included worry (57\%), stress/tension (51\%), amount of sleep (47\%), energy (43\%), and mood (39\%). Table 4 provides a summary of study results related to changes in health status for the study sample.

The level of depression was examined using the CES-D. The total score of the CES-D is the sum of all item responses and can range from 0 to 60 with a cutoff score of 16 or greater indicating significant depressive symptoms in the general population (Radloff, 1977). The median score for caregiver depressive symptoms was 12 indicating that on average, caregivers' scores reflect no depressive symptoms (0-15). Forty-nine caregivers had scores of 0-15 indicating no signs of clinical depression. Eleven caregivers (14.7\%) had scores of 16-20 indicating mild distress. Eleven caregivers (14.7\%) had scores of 22-30 indicating moderate distress and three caregivers (4.0\%) had scores of greater than 31 which indicated severe distress.

\section{Specific Aim Two}

Specific Aim Two was to document the objective health factors (BMI, number of prescription medications, number of physician office visits, and number of health problems) and the relationship between objective health factors and age of African American women who are family caregivers of persons with ESRD.

Because most of the caregivers were young to middle-aged adults, correlations could not be performed by age category however the associations could be examined using age as a continuous variable. The research questions were revised to examine the relationships between caregiver age and BMI, number of prescription medications, number of physician office visits in the past 6 months, and number of health problems. Research questions 2(a), 2(b), 2(c), and 2(d) were answered using Spearmans product moment correlation analysis to examine the interrelationship among the study variables. Prior to computing correlation estimates, graphic plotting of the relationship between the independent variable (caregiver age) and dependent variables (BMI, number of prescription medications, number of visits to health care provider, and number of health problems) was performed to allow for a visual examination of variable relationships and to determine if these relationships were linear. Data that did not demonstrate a linear relationship were analyzed using Spearman's correlation coefficient analysis. 
Table 3. Perceived Health Status in Family Caregivers of Persons with End Stage Renal Disease $(\mathrm{N}=75)$.

\begin{tabular}{lc}
\hline Health Status Level & $\mathrm{n}(\%)$ \\
\hline Excellent & $8(10.7)$ \\
Very Good & $17(22.7)$ \\
Good & $29(38.7)$ \\
Fair & $20(26.7)$ \\
Poor & $1(1.2)$ \\
\hline
\end{tabular}


Table 4. Changes in Health Status Associated with Caregiving $(\mathrm{N}=75)$.

\begin{tabular}{|c|c|c|c|c|}
\hline Variables & $\begin{array}{c}\text { Some } \\
\text { Change } \\
n(\%)\end{array}$ & $\begin{array}{c}\text { Moderate } \\
\text { Change } \\
\mathrm{n}(\%)\end{array}$ & $\begin{array}{c}\text { Great } \\
\text { Change } \\
n(\%)\end{array}$ & $\begin{array}{c}\text { Bad } \\
\text { Change } \\
n(\%)\end{array}$ \\
\hline Worry* & $15(20)$ & $22(29)$ & $18(24)$ & $43(57)$ \\
\hline Stress/tension* & $15(20)$ & $23(31)$ & $18(24)$ & $38(51)$ \\
\hline Amount of sleep* & $24(32)$ & $26(35)$ & $8(11)$ & $35(47)$ \\
\hline Energy* & $23(31)$ & $21(28)$ & $18(24)$ & $32(43)$ \\
\hline Mood* & $21(28)$ & $26(35)$ & $16(21)$ & $29(39)$ \\
\hline Weight* & $29(39)$ & $27(36)$ & $8(11)$ & $23(31)$ \\
\hline Exercise* & $27(36)$ & $13(17)$ & $12(16)$ & $25(33)$ \\
\hline Time for family and friends & $33(44)$ & $24(32)$ & $10(13)$ & $20(27)$ \\
\hline Amount of food & $27(36)$ & $23(33)$ & 13(17) & $15(20)$ \\
\hline Quality of food & $28(37)$ & $19(25)$ & $17(23)$ & $10(13)$ \\
\hline Alcohol & $9(12)$ & $4(5)$ & $1(1)$ & $6(8)$ \\
\hline Self-confidence & $47(63)$ & $16(21)$ & $6(8)$ & $6(8)$ \\
\hline Respect for self & $50(67)$ & $14(19)$ & $4(5)$ & $4(5)$ \\
\hline
\end{tabular}

Note. *Asterisks reflect those areas that $>30 \%$ of respondents reported the change as bad. 
BMI was calculated by using the Center for Disease Control formula, weight in kilograms divided by the square of height in meters. The mean BMI for caregivers was 31.2 indicating that on average this sample of caregivers was obese. One caregiver $(1.3 \%)$ was underweight. Fourteen caregivers (18.4\%) had a normal BMI; however, 60 caregivers $(78.9 \%$ ) had BMI levels that fell into the overweight and obese categories (see Table 5).

The mean number of prescription medications was $2.42(S D=2.75)$. Twenty-eight caregivers $(37.3 \%)$ reported using $1-5$ prescription medications. Fourteen caregivers (18.7\%) reported using 6-10 prescription medications and one caregiver $(1.3 \%)$ reported using more than 10 prescription medications. The most commonly prescribed medications for the sample were anti-hypertensive agents $(48 \%)$, anti-diabetic drugs $(17.3 \%)$, hormone replacement therapy (18.7\%), arthritis medications (12.0), antihyperlipidemia agents $(6.7 \%)$, and anti-anxiety medications $(5.3 \%)$. One caregiver also reported using transplant medications as she was a kidney transplant recipient (see Table $5)$.

The mean number of physician office visits in the past 6 months was 2.72 $(S D=13.8)$. Fifty-six caregivers $(74.7 \%)$ reported visiting a physician at least 1-5 times in the past six months. Six caregivers $(8 \%)$ reported visiting a physician at least 6-10 times in the past six months and one caregiver $(1.3 \%)$ reported visiting more than 10 times in the past six months.

The mean number of health problems that caregivers reported was 4.83 $(S D=4.05)$. Thirty-two caregivers $(42.7 \%)$ reported $1-5$ health problems. Nineteen caregivers $(25.3 \%)$ reported $6-10$ health problems and nine caregivers $(12.0 \%)$ reported greater than 10 health problems (see Table 5). The most commonly reported health problems included hypertension (48\%), visual problems $(57.3 \%)$, arthritis (28\%), GI problems (i.e., ulcers, stomach pain, diarrhea; 26.7\%), diabetes (24\%), menopause $(22.7 \%)$, stress $(21.3 \%)$, anxiety $(18.7 \%)$, and obesity $(14.7 \%)$. Two caregivers reported that like the patients they were caring for they too had renal failure (see Table 5).

Spearmans product moment correlations were calculated between caregiver age and BMI, number of prescription medications, number of visits to health care provider, and number of medical problems reported by African American family caregivers. The analysis between caregiver age and BMI revealed a non-significant correlation $(r=0.121$, $\mathrm{p}=.189$ ). Therefore, increased caregiver age was associated with a non-significant increase in BMI. A significant positive correlation was found between number of prescription medications and caregiver age $(\mathrm{r}=0.39 ; \mathrm{p}=0.000)$. Findings revealed that the older the caregiver the greater use of prescription medications. A non-significant correlation was found between number of physician office visits and caregiver age $(\mathrm{r}=.01$, $\mathrm{p}=.923$ ). As expected a significant positive correlation was found between number of reported medical problems and caregiver age $(\mathrm{r}=.52, \mathrm{p}=.000)$. Therefore, older caregiver age was associated with greater number of reported medical problems. 
Table 5. Frequency and Percentage of Objective Health Factors Reported by Caregivers $(\mathrm{N}=75)$.

\begin{tabular}{|c|c|c|c|c|}
\hline Objective Health Factor & $\mathrm{M}$ & SD & $\mathrm{n}$ & $\%$ \\
\hline Body mass index (percentage) & $31.29 \%$ & 7.08 & & \\
\hline Underweight & & & 1 & 1.3 \\
\hline Normal & & & 14 & 18.4 \\
\hline Overweight & & & 21 & 27.6 \\
\hline Obese & & & 39 & 51.3 \\
\hline$\underset{0}{\text { Number of prescription medications }}$ & 2.42 & 2.75 & & \\
\hline $1-5$ & & & 28 & 37.3 \\
\hline $6-10$ & & & 14 & 18.7 \\
\hline$>10$ & & & 1 & 1.3 \\
\hline $\begin{array}{l}\text { Physician office visits } \\
\quad 0\end{array}$ & 2.72 & 13.8 & & \\
\hline $1-5$ & & & 56 & 74.7 \\
\hline $6-10$ & & & 6 & 8 \\
\hline$>10$ & & & 1 & 1.3 \\
\hline $\begin{array}{l}\text { Number of medical problems } \\
0\end{array}$ & 4.83 & 4.05 & & \\
\hline $1-5$ & & & 32 & 42.7 \\
\hline $6-10$ & & & 19 & 25.3 \\
\hline$>10$ & & & 9 & 12.0 \\
\hline $\begin{array}{l}\text { Reported prescription medications } \\
\text { No prescription medications }\end{array}$ & & & & \\
\hline Anti-hypertensive agents & & & 36 & 48.0 \\
\hline Hormone replacement & & & 14 & 18.7 \\
\hline Anti-diabetic agents & & & 13 & 17.3 \\
\hline Arthritis drugs & & & 9.0 & 12.0 \\
\hline Anti-hyperlipidemia agents & & & 5.0 & 6.7 \\
\hline Anxiolytics & & & 4.0 & 5.3 \\
\hline $\begin{array}{l}\text { Reported health problems } \\
\text { No health problems }\end{array}$ & & & & \\
\hline Hypertension & & & 36 & 48.0 \\
\hline Visual problems & & & 43 & 57.3 \\
\hline Arthritis & & & 21 & 28.0 \\
\hline GI problems & & & 20 & 26.7 \\
\hline Diabetes & & & 18 & 24 \\
\hline Menopause & & & 17 & 22.7 \\
\hline Stress & & & 16 & 21.3 \\
\hline Anxiety & & & 14 & 18.7 \\
\hline Obesity & & & 11 & 14.7 \\
\hline Renal Failure & & & 2 & 2.7 \\
\hline
\end{tabular}




\section{Specific Aim Three}

Specific Aim Three was to document the relationship between the perceived health status and age of African American women who are family caregivers of persons with ESRD.

Research question 3 was answered using Spearman's correlation coefficient analysis because data were not normally distributed. Correlation analysis was computed to determine the interrelationships among the study variables. To determine if this relationship between the independent and dependent variables were linear, graphic plotting was performed to provide a visual examination of the variable relationships. The relationship between the independent variable (age) and dependent variable (perceived health status) revealed a significant weak positive correlation $(\mathrm{r}=.270, \mathrm{p}=0.019)$. As expected, findings revealed that older caregivers report poorer health status.

\section{Specific Aim Four}

Specific Aim Four was to identify demographic factors (age, level of education, and socioeconomic status) and objective and subjective health factors that predict the perceived health status as reported by African American women who are family caregivers of persons with ESRD.

Research question 4 was answered by using a multiple regression analyses to determine which variables predicted the perceived health status of African American women who were family caregivers of person with ESRD. A stepwise multiple regression analysis was performed to determine which independent variables best predicted the dependent variable. Prior to regression analysis, Spearman's correlation coefficient analyses were performed to determine the possible predictor variables for inclusion in the regression analysis. Significant positive correlations were found between caregiver health status (higher scores indicate poorer health) and number of prescription medications $(\mathrm{r}=0.44, \mathrm{p}=.000)$, number of visits to health care provider in the past 6 months $(\mathrm{r}=0.42, \mathrm{p}=.000)$, number of health problems $(\mathrm{r}=0.33, \mathrm{p}=.003)$, and caregiver age $(\mathrm{r}=0.270, \mathrm{p}=.019)$. A non-significant correlation was found between caregiver health status and total score of CES-D $(r=0.213, \mathrm{p}=.066)$. Furthermore, higher scores of caregiver perceived health status were associated with caregivers who reported consuming more prescription medications, reported more visits to a health care provider, reported more health problems, and those caregivers who were older. A non-significant inverse relationship was found between caregiver health status and the level of caregiver education $(\mathrm{r}=-0.202, \mathrm{p}=.085)$. Thus, the caregivers who reported lower levels of education experienced higher levels of perceived health status.

Utilizing these bivariate results, the demographic factors and objective and subjective health factors with significant linear relationships with the dependent variable were entered into the multiple regression analyses to determine which variables predicted the dependent variable. The degree of the linear relationship between independent and dependent variables was used to determine which variables were entered into the 
regression model. A weak linear relationship is considered if $\mathrm{r}$ is .10 to .29 , a moderate linear relationship is considered if $r$ is .30 to .50 , a strong linear relationship exists if $r$ is .50 or above (Burns \& Grove, 2005). The conceptual framework and previous caregiving research studies were used to determine which independent variables would be considered for entry into the regression analysis.

Multiple regression analysis was performed to determine the amount of the variance of perceived health status scores was explained by each predictor variable, the direction of the relationship, and the significance of the relationship of the predictor variable with the dependent variable. Predictor variables included in the regression analysis were number of prescription medications $(\mathrm{r}=0.44, \mathrm{p}=.000)$, number of physician office visits in the past 6 months $(\mathrm{r}=0.42, \mathrm{p}=.000)$, number of health problems $(\mathrm{r}=0.33$, $\mathrm{p}=.003)$, caregiver age $(\mathrm{r}=0.019, \mathrm{p}=.270)$ and total score of CES-D $(\mathrm{r}=0.213, \mathrm{p}=.066)$. The significant variables included were number of prescription medications, physician office visits in the past 6 months, number of health problems, and caregiver age. Total score of CES-D was a non-significant variable. The regression model for caregiver perceived health status indicated that five variables - number of prescription medications, number of visits to health care provider in the past 6 months, number of health problems, caregiver age, and total score of CES-D explained $31 \%(\mathrm{p}=.000)$ of the total variance. Thus, caregivers who reported consuming more prescription medications, reported more physician office visits in the past 6 months, reported more health problems, and those caregivers who were older reported lower perceived health status.

Utilizing the bivariate results mentioned above, a separate multiple regression analysis using stepwise regression was conducted for each of the outcome variables (demographic factors and objective and subjective health factors). Statistically significant predictor variables included in the regression analysis were number of prescription medications, physician office visits in the past 6 months, number of health problems, and caregiver age. Of the variables included in this model, the best predictors of perceived health status were number of health problems and doctors visits. The amount of variance explained by these variables was small $\left(r=0.48, \mathrm{R}^{2}=24\right)$.

Multicollinearity was assessed by conducting regression diagnostic analyses. The presence of multicollinearity amongst study variables can lead to substantial $\mathrm{R}^{2}$ but statistically insignificant coefficients; unstable regression coefficients; unexpected size of coefficients; and signs (e.g. negative versus positive coefficients) that are unexpected (Munro, 2005). Therefore, highly intercorrelated independent variables should be avoided. In order to detect the presence of multicollinearity amongst independent variables, examination of tolerance, variance inflation, and condition index estimates must be conducted. Tolerance, variance inflation, and condition index estimates were computed for each predictor variable. For each predictor variable within the model, tolerance values are between .940 and 1.000. Thus, the tolerance of all predictor variables were near 1.00, which indicates that the predictor variables in the model were uncorrelated (Munro, 2005). The variance inflation factors for the predictor variables within the study model ranged from 1.000-1.064 and the condition indices for the study 
model ranged from 1.000-3.266. A condition indices of $<30$ indicated the absence of multicollinearity; therefore, multicollinearity was not a problem in this analysis.

\section{Specific Aim Five}

Specific Aim Five was to document the health promotion behaviors as reported by African American women who are family caregivers of persons with ESRD.

Prior to analyzing this question, health promotion behaviors reported by African American women family caregivers were categorized by the investigator into five common behaviors. The most common behaviors reported focused on nutrition, exercise, modifying stress, spirituality/faith, and following physician orders and taking medication as ordered (see Table 6). Forty-four caregivers (58.7\%) reported that they practiced proper nutritional measures. Forty-three caregivers $(57.3 \%)$ reported that they practiced exercise as a health promotion behavior. Thirty-one caregivers $(41.3 \%)$ reported that they practiced different measures to modify their stress level. Twenty-three caregivers $(30.7 \%)$ reported that they practiced faith/spirituality measures. Nineteen caregivers $(25.3 \%)$ reported following physician or health care provider orders or took medication as prescribed in order to stay healthy. Twelve caregivers did not report any specific health promotion behaviors. Sixty-one caregivers $(81.3 \%)$ reported that they practiced $1-5$ health promotion behaviors in order to stay healthy. Two caregivers $(2.7 \%)$ reported that they practiced 6-10 health promotion behaviors in order to stay healthy. 
Table 6. Frequency and Percentage of Health Promotion Behaviors Reported by Caregivers $(\mathrm{N}=75)$.

\begin{tabular}{lcc}
\hline Reported health promotion behaviors & $\mathrm{n}$ & $\%$ \\
\hline Nutrition & 44 & 58.7 \\
Exercise & 43 & 57.3 \\
Modify stress & 31 & 41.3 \\
Faith/spirituality & 23 & 30.7 \\
Following physician orders/taking medication & 19 & 25.3 \\
\hline
\end{tabular}

Note: $\mathrm{N}>75$ due to some caregivers reporting several health promotion behaviors. 


\section{CHAPTER 5. DISCUSSION AND IMPLICATIONS}

\section{DISCUSSION}

The perceived health status of African American women who are family caregivers of persons with ESRD is understudied. Therefore, the purpose of this study was to identify the predictors of perceived health status of African American women who are family caregivers of persons with ESRD. In this study, on average the caregivers rated their health as good, however a significant number reported their health as fair or poor. In 10 of 16 areas, many caregivers reported bad changes in their health. Areas that were problematic were exercise and weight, sleep, mood, worry, stress/tension, energy, time for self, and time for family and friends. These finding suggest that many aspects of their lives were affected by having the caregiver role and that treatment strategies should be developed to address these problems because they compromise caregiver health status.

Dilworth-Anderson and Gibson (1999) suggest that African American caregivers when compared to White caregivers often have a combination of factors that may lead to poor caregiving outcomes including more health problems, higher mortality rates, and less use of formal support services. The knowledge gained by conducting this secondary data analysis could provide health care providers with new information to develop resources and interventions that improve the health status of African American female caregivers. Moreover, health care providers must be well trained and informed of the caregivers' perceptions of their health status and health promotion behaviors to provide a partnership that leads to improved health outcomes of the caregiver.

Improving the health status of these caregivers could in turn assist these caregivers to provide better care to family members with ESRD. Even though published research indicates that women are the primary caregivers the population studied has been primarily Caucasian women. Few studies include African American women caregivers and examine their health status and even fewer of these studies include caregivers of persons diagnosed with ESRD.

\section{DEMOGRAPHIC FINDINGS}

In the initial study conducted by Harris (2003), findings were similar to national data regarding the high percentage of female caregivers. The current study was limited to African American women to address study aims. The mean caregiver age was 47 years. This finding is consistent with a published national study (National Alliance for Caregiving, 2004) which indicated that the mean age of caregivers in years was 46 . With respect to relationship to the patient, most caregivers were parents $(37.3 \%)$ or wives $(31.6 \%)$. The majority of patients and caregivers lived in the same residence $(62.7 \%)$. The marital status of the caregivers were equal with respect to being single $(38.7 \%)$ or married (41.3\%). Several of the caregivers were divorced $(13.3 \%)$, widowed $(5.3 \%)$, or separated $(1.3 \%)$. These findings are not surprising because national data indicate that African American caregivers are less likely to be married than Caucasian caregivers 
(National Alliance for Caregiving, 2004). The mean education level was 13 years $(\mathrm{SD} \pm 2.6)$. The mean income of the caregivers was $\$ 23,317.53$ ( $\mathrm{SD} \pm \$ 18,492.25$ ). However, 20 of the caregivers omitted this data which is not uncommon in studies that include African American participants. Caregivers provided an average of 27.03 hours of care each day and provided care for an average of 49.13 months. These findings are consistent with national studies except, many participating caregivers reported providing care to their children $(37.3 \%)$ and only $31.7 \%(\mathrm{n}=24)$ were spousal caregivers. These findings were not surprising because African Americans are at risk for developing ESRD at an earlier age than Caucasians due to uncontrolled diabetes and hypertension. This finding was supported by a study that included caregivers of patients with ESRD (Wicks, et al., 1997). Studies have also shown that African Americans are more likely to experience hypertension, retinopathy, and ESRD compared to Caucasian Americans (Konen \& Summerson, 1999).

\section{Specific Aim One}

Aim One identifies the level of perceived health status reported by of African American women who are family caregivers of persons with ESRD

Caregivers on average $(\mathrm{n}=29,38.7 \%)$ rated their health as good; however, 21 (28\%) caregivers rated their health as either fair or poor. This finding is consistent with the rate reported in the initial study conducted by Harris (2003), which included both African American and Caucasian American participants. This finding is also consistent with a study conducted by McDonald and colleagues (2005). These investigators reported that many African American female caregivers reported poor health.

Caregivers were also asked to identify changes in their health status in predetermined areas, the degree of change (e.g. some, moderate or great change), and whether the change was good or bad. Caregivers reported both physical and mental health changes since becoming a caregiver. Caregivers reported several negative changes in health associated with the caregiving experience. The most frequently reported bad changes included worry (57\%), stress/tension (51\%), amount of sleep (47\%), energy $(43 \%)$, and mood (39\%). These findings are consistent with other caregiving studies that assessed changes in caregiver health since becoming a caregiver (McConnell, 1994; \& Pinquart \& Sorensen, 2005). Other investigators have documented that the caregiver's well-being may not change based on illness characteristics of the care recipient but rather the caregiver's appraisal of his or her situation and coping capacity (Gitlin, Winter, Dennis, \& Hauck, 2006). McConnell (1994) and Pinquart and Sorensen (2005) found that caregivers experience change in both physical health and mental health after becoming a caregiver. Snyder and Keefe (1985) concluded that caregivers report that their health status has declined since providing care to a family member.

The level of depressive symptoms was examined using the CES-D. The mean scores for caregiver mental health (depressive symptoms) were 12 indicating that as a whole, caregivers' scores reflected little to no depressive symptoms. Forty-nine caregivers had scores of 0-15 indicating no signs of clinical depression. Eleven caregivers 
(14.7\%) had scores of 16-20 indicating mild distress. Eleven caregivers (14.7\%) had scores of 22-30 indicating moderate distress and three caregivers (4.0\%) had scores of greater than 31 which indicated severe distress. These findings are supported by the initial study conducted by Harris (2003).

There have been many caregiving studies conducted that examined the levels of depressive symptoms amongst caregivers. Schultz (1997) stated that caregivers, when compared to population norms or control groups, report elevated levels of depressive symptoms. However, previous research indicates that African American caregivers on average experience low levels of depression (Dilworth-Anderson, 1997; Lawton, Rajogopal, Brody \& Klebal, 1992; Martin, 2000; Williams, Dilworth-Anderson, \& Goodwin, 2003). Similarly, Dilworth-Anderson and colleagues (1999) found that almost $20 \%$ of the caregivers in their study of 187 African American caregivers of dependent elders were emotionally distressed. Lee and colleagues (2001), in a study of caregivers of older adults found that $27 \%(\mathrm{n}=38)$ of caregivers had CES-D scores of 16 and above. However, Williams and colleagues (2003) also found that some caregivers reported a relatively low score of seven and others reported a relatively high score of 25 . These findings are consistent with the current study as 49 caregivers had no signs of clinical depression while three caregivers who had scores greater than 31, which indicated severe distress.

There are several plausible explanations for the level of depressive symptoms reported by these caregivers. Haley and colleagues (1996) reported that African American caregivers have higher levels of self-efficacy in managing caregiving problems. Moreover, Dilworth-Anderson and colleagues (2002) suggested that the lack of psychological distress found in African American caregivers may be due to strength of their family resources and religious coping. This may be true for participants in this current study. Jones-Cannon and Davis (2005) suggest that religion, prayer, and faith in God are instrumental in helping African American daughters cope with caregiving. Many caregivers in the current study reported religious activities and faith based activities as health promotion activities. The health promotion activities reported by caregivers in the current study may provide a mechanism of coping for these caregivers. Despite these activities, $51 \%$ reported stress/tension and 39\% reported negative mood changes.

\section{Specific Aim Two}

Aim Two documents objective health factors (BMI, number of prescription medications, number of visits to health care provider, and number of health problems) and the relationship between objective health factors and age of African American women who are family caregivers of persons with ESRD.

Weight gain is also a common health problem for female caregivers. In the current study, BMI was calculated by using the Center for Disease Control formula, weight in kilograms divided by the square of height in meters. The mean BMI for caregivers was 31.2 indicating that on average this sample of caregivers was obese. Sixty caregivers $(78.9 \%)$ fell into the overweight and obese categories. This finding is 
particularly interesting due to the fact that 43 caregivers reported that they exercised in order to stay healthy. Twenty-three caregivers also reported a bad change in their health related to weight since becoming a caregiver. Other research studies have shown that female caregivers experience a greater increase in weight than control groups (Vitaliano, Zhang, \& Scanlan, 2003). Wilcox and colleagues (2005) determined that African American female caregivers have a significantly higher mean body mass index than White female caregivers $(\mathrm{t}(26)=-2.25, \mathrm{p}=0.03)$. This high BMI puts caregivers at increased risk for health problems such as hyperlipidemia, hypertension, diabetes, cardiovascular disease, and arthritis. Forty-eight percent of caregivers in the current study reported that they were diagnosed with hypertension and $24 \%$ of caregivers reported that they were diagnosed with diabetes. Thus, findings from the current study were supported by previous research studies.

The mean number of prescription medications was $2.42(S D=2.75)$. Twenty-eight caregivers $(37.3 \%)$ reported using 1-5 prescription medications. Fourteen caregivers (18.7\%) reported using 6-10 prescription medications and one caregiver $(1.3 \%)$ reported using more than 10 prescription medications. The most commonly prescribed medications for the sample were anti-hypertensive agents (48\%), anti-diabetic drugs $(17.3 \%)$, hormone replacement therapy (18.7\%), arthritis medications (12.0), antihyperlipidemia agents $(6.7 \%)$, and anti-anxiety medications (5.3\%). One caregiver also reported using transplant medications. In support of the current study, Shultz and colleagues (1997) concluded that strained caregivers rated their health as lower and use more prescription medications compared to non-strained caregivers and non-caregivers. The high number of prescription medications may be explained by the fact that many of these caregivers were older. Often as people age the number of reported chronic illnesses that they have also increases which may account for the high number of reported prescription medications in the current study sample.

The mean number of visits to health care provider in the past 6 months was 2.72 $(S D=13.8)$. Fifty-six caregivers reported visiting a health care provider at least 1-5 times in the past six months. Six caregivers reported visiting a health care provider at least 6-10 times in the past six months and one caregiver reported visiting more than 10 times in the past six months. In support of the current study research indicates that caregivers compared to non-caregivers have higher levels of health care utilization as evidenced by both a greater number of prescription medications and a greater number of recent physician visits (Haley, Levine, \& Brown, 1987; Shua-Haim et al., 2001; Zhang et al., 2006). Because there was not a comparison of caregivers to non-caregivers in the current study there may be other plausible explanations for this level of provider visits including the high number of older adults participating in the study and multiple chronic illnesses reported by the study sample.

The mean number of health problems that caregivers reported was 4.83 $(S D=4.05)$. Thirty-two caregivers reported $1-5$ health problems. Nineteen caregivers reported 6-10 health problems and nine caregivers reported greater than 10 health problems. The most commonly reported health problems included hypertension, visual problems, arthritis, GI problems (i.e., ulcers, stomach pain, diarrhea), diabetes, 
menopause, stress, anxiety, and obesity. Two caregivers reported that like the patients they were caring for they too had renal failure. In support of the current study, several investigators found that caregivers report higher rates of diabetes, arthritis, ulcers, and anemia than the general population (Bakas \& Burgener, 2002; Bakas, Pressler, Johnson, Nauser, \& Shaneyfel, 2006; McConnell, 1994; \& Pruchno \& Potashnik, 1989). Not only are caregivers at risk for poor physical health they also can be at risk for mortality. Schulz and Beach (1999) found that strained caregivers with chronic diseases were at risk for mortality. Thirty-three percent $(\mathrm{n}=392$ caregivers) of these individuals died within 4 years of study participation. Research also indicates that female caregivers experience and report more chronic conditions such as arthritis, hypertension and heart trouble (Pruchno \& Potashnik, 1989; Zhang, Vitaliano, \& Lin, 2006). Rosenman and colleagues (1994) found that some of the most frequently reported symptoms were headaches, tension and nervousness, leg pain, and backache $(p<0.05)$. Many of these reported symptoms were common in the current study sample. Anxiety and stress were present in $40 \%$ of the participants in the current study. In general, these caregivers reported multiple chronic health problems and were caring for persons with a chronic health problem. The health of these caregivers must be maintained if they are to continue providing care to their family members with ESRD.

African Americans experience poorer physical health than Whites (Underwood, Buseh, Canales, Powe, Dockery, et al., 2005; United States Department of Health and Human Services, 2004). African Americans when compared to Whites are twice as likely to have diabetes (Hosey, Gordon, \& Levine, 1999). Research also indicates that African American women experience an even greater prevalence of diabetes than do African American men (Hosey, et al., 1999; Lipton, Liao, Cao, Cooper, \& McGee, 1993). African Americans also experience more complications from diabetes including hypertension (Konen, Summerson, Bell, \& Curtis, 1999), retinopathy (Harris, Sherman, \& Georgopoulos, 1999) and ESRD (Hosey et al., 1999). In the current study, 48\% of caregivers reported having hypertension and $24 \%$ of caregivers reported having diabetes and two patients were kidney transplant recipients. These diseases separately or in combination place these caregivers at risk for developing ESRD. Two caregivers were kidney transplant recipients however we did not ask if they became transplant recipients before or after taking on the caregiver role.

\section{Specific Aim Three}

Aim Three documents the relationship between the perceived health status and age of African American women who are family caregivers of persons with ESRD.

The relationship between the independent variable (age) and dependent variable (perceived health status) was examined using Spearman's correlation coefficient analysis. A significant weak positive correlation was found between perceived health status and caregiver age. As expected, findings revealed that older caregivers report poorer health status. Studies have shown that age may or may not be affect the health status of the caregiver. Developmentally older adult caregivers compared to younger adult caregivers may expect to assume the role of caregiver as chronic illness and disability are often 
expected consequences of aging (Brody, 1985). Research also documents that as many as $60 \%$ of older adults in several studies attributed their health conditions and disability to the normal process of aging (Sarkisian, Liu, Ensrud et al., 2001; Gump, Matthews, Scheier, et al., 2001). Little caregiving research specifically addresses young caregivers. Younger adult caregivers often have multiple competing roles that include parenting, head of household, employee, and possible caregiver to multiple persons (Levine, Hunt, Halper, Hart, Lautz, \& Gould, 2005). Cain and Wicks (2000) document the significant positive relationship between caregiver age and burden.

Harwood and colleagues (2000) examined factors associated with perceived health status of 64 White family caregivers of community dwelling Alzheimer's disease patients. The researchers concluded that poor self-rated health was predicted by older caregiver age and greater depressive symptoms reported by the caregiver. This finding is also in support of the findings in the current study. Poorer self-rated health was associated with older caregivers in this study. This finding has also been reported in prior research among persons caring for patients with dementia (Haley, Levine, Brown, \& Bartolucci, 1987). Thus, due to the higher rates of health problems, older African American caregivers may experience lower perceived health which supports findings in the current study.

\section{Specific Aim Four}

Aim Four identifies demographic factors (age, level of education, and socioeconomic status) and objective and subjective health factors that predict the perceived health status as reported by African American women who are family caregivers of persons with ESRD.

Research question 4 was answered by using a multiple regression analyses to determine which variables predicted the perceived health status of African American women who were family caregivers of person with ESRD. A stepwise multiple regression analysis was performed to determine which independent variables best predict the dependent variable. Significant positive correlations were found between caregiver health status (higher scores indicate poorer health) and number of prescription medications $(\mathrm{r}=0.44, \mathrm{p}=.000)$, number of visits to health care provider in the past 6 months $(\mathrm{r}=0.42, \mathrm{p}=.000)$, number of health problems $(\mathrm{r}=0.33, \mathrm{p}=.003)$, caregiver age $(r=0.019, p=.270)$, and total score of CES-D $(r=0.213, p=.006)$. Furthermore, higher scores of caregiver perceived health status were associated with caregivers who reported consuming more prescription medications, reported more visits to a health care provider, reported more health problems, and those caregivers who were older. A non-significant inverse relationship was found between caregiver health status and the level of caregiver education $(\mathrm{r}=-0.202, \mathrm{p}=.085)$. Thus, the caregivers who reported lower levels of education experienced higher levels of perceived health status at the .085 significance level.

Multiple regression analysis was performed to determine the amount of variation

of perceived health status scores explained by each predictor variable, the direction of the 
relationship, and the significance of the relationship of the predictor variable with the dependent variable. Predictor variables included in the regression analysis were number of prescription medications $(\mathrm{r}=0.44, \mathrm{p}=.000)$, number of visits to health care provider in the past 6 months $(\mathrm{r}=0.42, \mathrm{p}=.000)$, number of health problems $(\mathrm{r}=0.33, \mathrm{p}=.003)$, caregiver age $(r=0.019, p=.270)$, and total score of CES-D score $(r=0.213, p=.006)$. The regression model for caregiver perceived indicated that five variables - number of prescription medications, number of visits to health care provider in the past 6 months, number of health problems, caregiver age, and total score of CES-D explained $31 \%$ $(p=.000)$ of the total variance. Thus, caregivers who report consuming more prescription medications, report more visits to a health care provider, report more health problems, and those caregivers who were older report lower perceived health status.

The best predictors of perceived health status were number of health problems and doctors visits. Because the best predictors of perceived health status were number of health problems and number of doctors visits the amount of variance explained by these variables was small $(\mathrm{r}=0.24)$ that were not captured in this study might better explain perceived health status in African American women who are family caregivers of persons with ESRD.

\section{Specific Aim Five}

For Aim Five we document the health promotion behaviors as reported by African American women who are family caregivers of persons with ESRD.

The most common behaviors reported by African American family caregivers were nutrition, exercise, modifying stress, spirituality/faith, following physician orders, and taking medication as ordered. Forty-four caregivers $(58.7 \%)$ reported that they practiced proper nutritional measures. Forty-three caregivers $(57.3 \%)$ reported that they practiced exercise as a health promotion behavior. Thirty-one caregivers $(41.3 \%)$ reported that they modified their stress level. Twenty-three caregivers $(30.7 \%)$ reported that they practiced faith/spirituality measures. Nineteen caregivers $(25.3 \%)$ reported following physician or health care provider orders or took medication as prescribed in order to stay healthy. Twelve caregivers did not report any specific health promotion behaviors. Sixty-one $(81.3 \%)$ caregivers reported that they practiced $1-5$ health promotion behaviors in order to stay healthy. Two caregivers reported $(2.7 \%)$ reported that they practiced 6-10 health promotion behaviors in order to stay healthy.

Connell (1994) who conducted a retrospective data analysis of 44 family caregivers found that one third of the participants reported that they ate less nutritiously, exercised less, and used more medications to promote sleep. Similar findings were reported by Acton (2002) who compared health-promoting self-care behaviors in 46 family caregivers to 50 demographically matched non-caregivers. The researcher concluded that family caregivers scored significantly lower on Importance of Self-Care, Health Responsibility, Physical Activity, Spiritual Growth, Interpersonal Relationships, Stress Management, Total Health-Promotion Actions, and Hours of Sleep $(p<0.01)$. In support of the reported finding above, Burton and colleagues (1997) compared preventive health behaviors in 434 spouse caregivers to 385 demographically matched non- 
caregivers. The researchers concluded that caring for a spouse with activity-of-daily living impairments significantly increased the risk for not getting enough rest, not having enough time to exercise, not being able to take enough time to recuperate from illness, and forgetting to take prescription medications. In the current study, participants reported negative changes in amount of sleep, worry, stress/tension, energy, mood, weight, and exercise.

McConnell (1994) also reported that the role of caregiver interferes with conducting health promotion behaviors. The researcher concluded that over one-third of the caregivers $(n=44,39 \%)$, reported that they eat less nutritiously since becoming a caregiver and 14 percent report that their appetite has declined. The researcher also found that almost one-half of the caregivers who smoke (43\%) report increasing the number of cigarettes smoked per day since becoming a caregiver. Forty percent of the participants reported that their physical health had been negatively affected by caring for their spouse.

Burton and colleagues (1997) conducted a secondary data analysis using a sample of more than 3,000 married, community-dwelling older persons, who were enrolled in a large Cardiovascular Health Study. The researchers concluded that high-level caregivers when compared to non-caregivers, did not get enough rest, did not participate in exercise regularly, did not have enough time to rest or recuperate from illness, and often forgot to take prescription medication $(\mathrm{p}<.000)$.

Even though there are several published studies documenting the health promotion behaviors of caregivers there are fewer published studies that document the health promoting behaviors of African American caregivers (McDonald, Brennan, \& Wykle, 2005; McDonald, Fink, \& Wykle, 1999; McDonald \& Wykle, 2003). McDonald and Wykle (2003) conducted a secondary data analysis of 66 African American and 110 White caregivers of impaired older adults to examine predictors of health-promoting behavior. The researchers concluded that the number of health-promoting behaviors was significantly different between African American and White caregivers, with White caregivers reporting a higher number of health promoting behaviors $(\mathrm{p}<0.05)$. In support of the reported finding above, McDonald and colleagues (2005) found that African American caregivers reported a significantly lower number of health-promoting behaviors than did White caregivers ( $\mathrm{t}$-value $=2.81, \mathrm{df}=393, \mathrm{p}<0.05$ ). Lower percentages of African Americans caregivers reported getting adequate sleep, eating breakfast, not smoking, and exercising when compared to Caucasian caregivers. This study also documented that African American female caregivers reported that they were overweight and that they exercised less than the participants in the other three groups (African American male, White male, White female). Even though the current study did not compare African American caregivers to Caucasian caregivers, similar changes in health status were reported by the participants in the current study including negative changes in worry, stress/tension, amount of sleep, energy, mood, weight, and exercise. 


\section{LIMITATIONS AND STRENGTHS}

This study had seven limitations. The following paragraphs will discuss each limitation in detail.

First, this study was a secondary data analysis of data from a larger study. Conducting a secondary data analysis can lead to threats to internal and external validity (Burns \& Grove, 2004). However, despite this limitation findings from the current study are validated by findings from the initial study (Harris, 2003) and are supported by research studies mentioned in the discussion of the study results.

Second, this study and the initial study (Harris, 2003) used a cross-sectional, descriptive correlation design. This type of research design allows researchers to gather data from one point in time. Thus it does not reflect the totality of the caregivers' experiences. The caregivers had different levels of caregiving experiences, which could potentially decrease the external validity of the study findings. Therefore, the findings identifying the predictors of perceived health status of African American women who are family caregivers of persons with ESRD found in this study may not be reflective of the factors that influence this outcome over time. A longitudinal research study is needed to explore the significant predictors of perceived health status over time in family caregivers of persons with ESRD.

Third, a single-item, self-rated measure of perceived health status may not alone measure the objective physical health status of caregivers. However, researchers have found that self-rated health is a strong correlate of objective measures of health and predicts mortality better than either medical records or physician generated data (LaRue, Bank, \& Jarvik, 1979; Mossey \& Shapiro, 1982; Schultz \& Beach, 1999). In the initial study conducted by Harris (2003) significant correlations existed between the singleitem, self-evaluation of health and the number of prescription medications, doctor visits, and emergency room visits therefore supporting the validity of this measurement. In the current study, significant correlations existed between the single item, self-evaluation of health and the number of prescription medications, doctor visits, and number of health problems, which are all objective indicators of health status.

Fourth, most of the participants were from the metropolitan area. Therefore, the results of the study may not be reflective of the experiences reported by individuals who live in rural areas.

Fifth, the use of Phillips and Rempusheski's (1986) Severity of Caregiver's Disease Scale is a limitation of this study. This instrument has not been validated in caregivers of persons with ESRD.

Sixth, caregivers who are severely stressed, depressed, or burdened may not be represented in this study. Caregivers who experienced severe burden and stress from their day-to-day caregiving routines coupled with other responsibilities may not have participated in the primary study. Three caregivers in the current study had scores of greater than 31 which indicated severe distress. 
Seventh, caregivers who could not read or write were not represented in this study, which is a limitation.

Several limitations to this study exist; however, the current study has several strengths. The first strength is this study only included African American women family caregivers. Included in the current study were wives, daughters, parents, and other family relatives of patients with ESRD. Most of the previous studies in this area focus on Caucasian female participants who tend to be wives or daughters. Fewer studies include African American women caregivers and examine their health status; thus, this study was sorely needed. The second strength is the demographic characteristics of participants. There were many caregivers who were providing care to their children $(37.3 \%)$ and only $31.7 \%(n=24)$ were spousal caregivers. Caregivers in the current study were employed on average 23 hours per week and provided on average 27 hours of caregiving, thus for many caregivers the hours spent in caregiving was equivalent to a part-time job. In the current study, the majority of patients and caregivers lived in the same residence. This finding is not consistent with many caregiving studies that focus on Caucasian caregivers. In the current study almost $60 \%$ percent of the participants were single, divorced, separated, or widowed. These findings are not surprising because national data indicate that African American caregivers are less likely to be married than Caucasian caregivers. A third strength of the study was that the initial data were collected from three dialysis centers, which included participants from all socio-economic levels, thus increasing the external validity of findings.

\section{PRACTICE AND POLICY IMPLICATIONS}

Implications for both practice and policy have developed from the findings of this study. Implications for practice are based upon study findings related to the predictors of perceived health status. These findings could be used in practice to help health care providers predict possible poor health status and develop resources or interventions to improve the health status of these caregivers based on the findings from this study.

Specific interventions and resources for this population should be developed to improve the health status of African American female caregivers of persons with ESRD. The best predictors of caregiver perceived health status were number of health problems and number of doctor visits within the past 6 months. These findings suggest that the most effective interventions should be developed in order to address management of their chronic health problems. Although depressive symptoms were not a significant predictors of the outcome variable (perceived health status), depressive symptoms can influence how persons' perceive the world and self; therefore, an intervention to decrease or manage depressive symptoms would be useful for this population. Other notable findings from the current study included high BMIs, self-reported chronic disease such as diabetes and hypertension, depressive symptoms, and changes in health status such as anxiety, stress, weight, worry, and mood. Although these variables were not included in the prediction model, it is important to note that these are variables that can influence the way that caregivers of persons with ESRD may view their health and manage chronic 
diseases. Other interventions should focus on health promotion strategies in order to help caregivers maintain their health status. Interventions should focus on assessing caregiver's perceptions of their health status and developing specific interventions that help the caregiver to decrease their BMI, manage their chronic diseases, depressive symptoms, stress, and anxiety levels. Health care providers should be well trained and informed of the caregivers perceptions of values and health care beliefs in order to provide a partnership that leads to improved health outcomes of the caregiver. It is important for health care providers to assess caregivers and provide early interventions and support programs that would benefit caregivers. Interventional programs that included ways for caregivers to manage depressive symptoms would be beneficial for this population. Improving the health status of these caregivers could in turn assist these caregivers to provide better care to family members with ESRD.

\section{Theoretical Implications}

Study findings provide support for the conceptual model that focuses on demographic factors (age, level of education, marital status, and socioeconomic status) and subjective (perceived health status, perceived change in health status, and depressive symptoms) and objective health indicators (number of medications, BMI, number of physician office visits, and number of health problems) as correlates of health status in a sample of African American women who are caregivers of persons with ESRD (see Figure 1). The conceptual framework that guided the current study is based on Flaskerud's Vunerable Populations Model (Flaskerud \& Winslow, 1998) because the focus of the study is on African American women who are caregivers at risk for impaired health status. Of the variables included in this study, the best predictors of perceived health status were number of health problems and doctors visits. Thus, study data provided partial support for the conceptual model used in this study. Variables that were not significantly correlated to perceived health status were level of education, marital status, socioeconomic status, perceived change in health status, and BMI. However, these are important variables because they may influence the caregiver's perceived health status. The model serves as a guide to holistically examine factors that can influence the health status of African American women who are caregivers of persons with end stage renal disease. The conceptual model states that African American female caregivers are at risk not only because of their role as informal caregivers but also because they are women and persons of color. Female informal caregivers can also be considered a social group that is vulnerable to poor health outcomes due to the limited amount of resources available to them, as well as, the increased exposure to conditions (length of caregiving, ethnic minority, racism, and being a women) that can contribute to poor health status. The Vulnerable Populations Model is composed of interrelationships among resource availability, relative risk, and health status (Aday, 1994; Flaskerud \& Winslow, 1998). The model explains that resource availability includes socioeconomic and environmental resources. The concept of relative risk is explained by the ratio of poor health of people who lack resources and are exposed to the risks compared to people who receive resources and are not exposed to risk (Flaskerud \& Winslow, 1998). Health status is determined by disease prevalence and morbidity and mortality rates amongst the community. 
African American women are at risk for increased morbidity and mortality because they are disproportionately poor, members of a minority group, and informal caregivers. African American women caregivers often lack resources which further increase their risk for poor health status. The absence of resources is particularly problematic because ESRD often results in disability and loss of income for the effected person. African American women may experience lack of access to quality care (Williams \& Wilson, 2001) or may lack access to insurance coverage (Sotomayor \& Randolph, 1988) the absence of these resources can contribute to their vulnerability. The caregivers in the current study reported annual incomes of $\$ 23,317.53$ ( $\mathrm{SD} \pm 18,492)$. Twenty caregivers did not report an annual income level. These variables (lack of access to insurance coverage, exposure to risks, and racism) were not examined in the present study. These are variables that influence perceived health status. Due to the crosssectional design of the study and the use of secondary data analysis techniques, the relationship between these variables and perceived health status could not be determined. Another study that included variables that assessed caregiver's resources and other variables within the Vulnerable Populations Model would provide a better understanding of the relationship among these variables. Furthermore, a longitudinal design would provide a better understanding of the relationship among these variables overtime.

\section{Future Research}

There are five recommendations for future research. The first recommendation for future research would be to conduct a longitudinal study that examines predictors of perceived health status as this would allow researchers to gain understanding of the caregiver's experience over the course of the disease. The second recommendation for future research is to examine the relationship between perceived health status and variables such as access to health care and risk factors that African American women face in order to explore other possible predictors of perceived health status that are relevant to the Vulnerable Populations Model. The third recommendation is to examine whether cultural factors contribute to the perceived health status of African American women caregivers. The fourth recommendation for future research is to conduct an intervention study that help caregivers manage their risk factors for poor health status including obesity, chronic diseases, anxiety, stress, and depressive symptoms. The final recommendation for future research is to examine the differences between African American and Caucasian women who are caregivers of persons with ESRD.

\section{CONCLUSIONS}

In summary, this study provided support for the proposed conceptual framework that examined the predictors of perceived health status of African American women who are family caregivers of persons with ESRD. The women in this study overall rated their health as good; however, they reported many health problems, used multiple medications, reported anxiety and stress, changes in weight, sleep, and worry, and had high BMIs. In spite of these findings these women also reported participating in health promotion behaviors daily in order to enhance their health. The amount of perceived health status 
variance explained by the multiple regression analysis was small. This finding is important because it suggests that there are likely several factors that influence the perceived health status of these women. Even though these women had many diagnosed health problems, on average they perceived their health was good. There may be cultural and socioeconomic factors that that influenced this perceived good health status despite these diagnosed health problems. Their chronic health problems, rather than the role of caregiver, might also explain their symptoms of depression.

The health status and health outcomes of patients and families are the focus of nursing care and nursing research. ESRD affects both patients and their caregivers. These caregivers must maintain their health in order to maintain the caregiver role. ESRD is more common in African American families who are often not included in caregiving research studies. In this study caregivers reported multiple changes in health that could jeopardize their ability to continue to provide care. These caregivers also reported many health promotion behaviors including exercising, nutrition, and faith in God; however, they also reported diagnosed chronic health problems including diabetes, hypertension, and obesity. It is unclear how well caregivers manage these health problems; therefore, studies are needed to address this issue. Caregivers who adequately manage these chronic health problems may perceive their health as good compared to caregivers with poorly managed illnesses. Many of these caregivers reported depressive symptoms and bad changes in health status since becoming a caregiver. Most caregivers were obese. These findings are significant because if these problems are not addressed they place these caregivers at risk for more chronic health problems such as cardiovascular disease, diabetes, hypertension, or possibly end stage renal disease which is problematic because they are already at risk because of their African American ethnicity. Validation of these finding will provide support for developing early assessment parameters for at risk caregivers, health promotion interventions, and support groups that address the needs of these caregivers. 


\section{LIST OF REFERENCES}

Acton, G. (2002). Health-promoting self-care in family caregivers. Western Journal of Nursing Research, 24(1), 73-86.

Aday, L. A. (1993). At risk in America. The Health and Health Care Needs of Vulnerable Populations in the United States. Jossey-Bass Publishers, San Francisco.

Aday, L. A. (1994). Health status of vulnerable populations. Annual Review of Public Health, 15, 487-509.

Adler, N. E., Boyce, T., Chesney, M. A., Folkman, S., \& Syme, S. L. (1994). Socioeconomic status and health: The challenge of the gradient. American Psychology, 49, 15-24.

Bakas, T., \& Burgener, S. (2002). Predictors of emotional distress, general health, and caregiving outcomes in family caregivers of stroke survivors. Top Stroke Rehabilitation, 9(1), 34-45.

Bakas, T., Pressler, S., Johnson, E., Nauser, J., \& Shaneyfelt, T. (2006). Family caregiving in heart failure. Nursing Research, 55(3), 180-188.

Bedard, M., Koivuranta, A., \& Stuckey, A. (2004). Health impact on caregivers of providing informal care to a cognitively impaired older adult: Rural versus urban setting. Canadian Journal of Rural Medicine, 9(1), 15-23.

Belasco, A. G., \& Sesso, R. (2002). Burden and quality of life of caregivers for hemodialysis patients. American Journal of Kidney Diseases, 39(4), 805-812.

Bernheim, J. \& Korzets, Z. (1999). Home hemodialysis: Beware the psychological Impact on the helper and/or family. Nephrology Dialysis Transplantation, 14(4), 1031-1032.

Brody, E., Litvin, S., Hoffman, C., \& Kleban, M. (1992). Differential effects of daughters' marital status on their parent care experiences. The Gerontologist, 32, 58-67.

Bullock, K., Crawford, S., \& Tennstedt, S. (2003). Employment and caregiving: Exploration of African American caregivers. Social Work, 48(2), 150-162.

Bureau of the Census U.S. (2005). Informed, poverty, and health insurance coverage in the United States. Department of Commerce, Washington, D.C.

Burns, N., \& Grove, S. (2004). The Practice of Nursing Research: Conduct, critique, \& utilization (5th ed.). Philadelphia, Pennsylvania: W. B. Saunders Company. 
Burstrom, B. \& Fredlund, P. (2001). Self-rated health: Is it as good a predictor of subsequent mortality among adults in lower as well as in higher social classes? Journal of Epidemiology and Community Health, 55(11), 836-40.

Burton, L., Newsom, J., Schulz, R., Hirsch C., \& German, P. (1997). Preventative health behaviors among spousal caregivers. Preventative Medicine, 26, 162-169.

Calvin, A. (2004). Haemodialysis patients and end-of-life decisions: A theory of personal preservation. Journal of Advanced Nursing, 46(5), 558-569.

Campbell, A. (1998). Family caregivers: Caring for aging end stage renal disease partners. Advanced Renal Replacement Therapy, 5, 98-108.

Carver, C., \& Scheier, M. (1990). Principles of self-regulation. In: E. T. Higgins \& R. M. Sorrentino (Eds.), Handbook of Motivation and Cognition: Foundations of Social Behavior (pp. 3-52). Guilford, New York, NY.

Connell, C. (1994). Impact of spouse caregiving on health behaviors and physical and mental health status. American Journal of Alzheimer's Care and Related Disorders and Research, 9, 26-36.

Cox, C. (1993). Service needs and interests: A comparison of African-American and White caregivers seeking Alzheimer's assistance. American Journal of Alzheimer's Disease, 3, 343-349.

Cox, C., \& Monk, A. (1990). Minority caregivers of dementia victims: A comparison of Black and Hispanic families. Journal of Applied Gerontology, 9, 340-354.

Cox, C., \& Monk, A. (1996). Strain among caregivers: Comparing the experiences of African American and Hispanic caregivers of Alzheimer's relatives. International Journal of Aging and Human Development, 43, 93-105.

Dilworth-Anderson, P., Goodwin, P. Y., \& Williams, S. W. (2004). Can culture help explain the physical health effects of caregiving over time among African American caregivers? The Journals of Gerontology. Series B, Psychological Sciences and Social Sciences, 59(3), S138-145.

Edelman, C., \& Mandle, C. (Eds.). (1994). Health promotion throughout the life span. (3 ed.). St. Louis: Mosby.

Edelman, C., \& Mandle, C. (Eds.). (1998). Health promotion throughout the life span. (4 ed.). St. Louis: Mosby.

Ensel, W.M. (1986). Measuring depression: The CES-D scale. In: Lin N, Dean A, Ensel W, eds. Social support, life events, and depression. New York, NY: Academic Press, 51-70. 
Flaskerud, J., Lesser, J., Dixon, E., Anderson, N., Conde, F., Kim, S., et al. (2002).

Health disparities among vulnerable populations. Nursing Research, 51(2), 74-85.

Flaskerud, J., \& Tabora, B. (1998). Health problems of low income female caregivers of adults with HIV/AIDS. Health Care for Women International, 19, 23-36.

Flaskerud, J., \& Winslow, B. (1998). Conceptualizing vulnerable populations healthrelated research. Nursing Research, 47(2), 69-78.

Flaskerud, J. H., \& Lee, P. (2001). Vulnerability to health problems in female informal caregivers of persons with hiv/aids and age-related dementias. Journal of Advanced Nursing, 33(1), 60-68.

Gitlin, L., Winter, L., Dennis, M., \& Hauck, W. (2006). Assessing perceived change in the well-being of family caregivers: Psychometric properties of the perceived change index and response patterns. American Journal of Alzheimer's Disease and Other Dementias, 21(5), 304-311.

Given, B. A., \& Given, C. W. (1998). Health promotion for family caregivers of chronically ill elders. In J. J. Fitzpatrick (Ed.), Focus on health issues in pediatric nursing (pp. 197-217). New York: Springer.

Gump, B., Matthews, K., Scheier, M., et al.(2001). Illness representations according to age and effects on health behaviors following coronary artery bypass graft surgery. Journal of the American Geriatrics Society, 49, 284-289.

Haley, W. E., Gitlin, L. N., Wisniewski, S. R., Mahoney, D. F., Coon, D. W., Winter, L., et al. (2004). Well-being, appraisal, and coping in African-American and Caucasian dementia caregivers: Findings from the reach study. Aging Mental Health, 8(4), 316-329.

Haley, W. E., Levine, E. G., \& Brown, S. L. (1987). Psychological, social, and health consequences of caring for a relative with senile dementia. Journal of the American Geriatrics Society, 35, 405.

Haley, W. E., West, C., Wadley, V., Ford, G., White, F., Barrett, J., et al. (1995). Psychological, social, and health impact of caregiving: A comparision of Black and White dementia family caregivers and noncaregivers. Psycholology and Aging, 10(4), 540-552.

Han, B., \& Haley, W. E. (1999). Family caregiving for patients with stroke: Review and analysis. Stroke, 30, 1478-1485. 
Harris, E., Sherman, S., \& Georgopoulos, A. (1999). Black-white differences in risk of developing retinopathy among individuals with type 2 diabetes. Diabetes Care, 22(5), 779-783.

Harris, T. T., Thomas, C. M., Wicks, M. N., Faulkner, M. S., \& Hathaway, D. K. (2000). Subjective burden in young and older African-American caregivers of patients with end stage renal disease awaiting transplant. Nephrology Nursing Journal, 27(4), 383-391, 355; discussion 392, 405.

Harris, T.T. (2003). Burden and health in caregivers of persons with kidney disease. Doctoral dissertation. University of Tennessee Center for the Health Sciences.

Harwood, D., Barker, W., Ownby, R., \& Duara, R. (2000). Caregiver self-rated health in Alzheimer's disease. Clinical Gerontologist, 21(4), 19-33.

Hinrichsen, G. \& Ramirez, M. (1992). Black and white dementia caregivers: A comparison of their adaptation, adjustment, and service utilization. The Gerontologist, 32, 376-381.

Hopkins, K. (2005). Facilitating sleep for patients with end stage renal disease. Nephrology Nursing Journal, 32(2), 189-195.

Hosey, G., Gordon, S., \& Levine, A. (1999). Type 2 diabetes in people of color. Nurse Practice Forum, 9(2), 109-114.

Idler, E. L. \& Benyamini, Y. (1997). Self-rated health and mortality: A review of twentyseven community studies. Journal of Health and Social Behavior, 38, 21-37.

Idler, E., \& Kasl, S. (1991). Health perceptions and survival: Do global evaluations of health status really predict mortality? Journal of Gerontology, 46(2), S55-65.

Idler, E., Kasl, S., \& Lemke, J. (1990). Self evaluated health and mortality among the elderly in New Haven, Connecticut, and Iowa and Washington Counties, Iowa, 1982-1986. American Journal of Epidemiology, 131, 91-103.

Kaplan, G., Barell, V., \& Lusky, A. (1988). Subjective state of health and survival in elderly adults. Journal of Gerontology: Social Sciences, 43, 114-120.

Kearney, B. \& Fleishcher, B. (1979). Development of an instrument to measure exercise of a self-care agency. Research in Nursing \& Health, 2, 25-34.

King, A., Oka, R., \& Young, D. (1994). Ambulatory blood pressure and heart rate Responses to the stress of work and caregiving in older women. Journals of Gerontology: Series A: Biological Sciences and Medical Sciences, 49, M239M245. 
Knight, B. G., Silverstein, M., McCallum, T. J., \& Fox, L. S. (2000). A sociocultural stress and coping model for mental health outcomes among African American caregivers in southern California. The Journals of Gerontology. Series B, Psychological Sciences and Social Sciences, 55(3), P142-150.

Konen, J., Summerson, J., Bell, R., \& Curtis, L. (1999). Racial differences in symptoms and complications-adults with type 2 diabetes mellitus. Ethnicity \& Health, 4, 3949.

Kubzansky, L., Berkman, L., Glass, T., \& Seeman, T. (1998). Is educational attainment associated with shared determinants of health in the elderly? Findings from the MacArthur Studies of Successful Aging. Psychosomatic Medicine, 60, 578-585.

Kuhlman, G. J., Wilson, H. S., Hutchinson, S. A., \& Wallhagen, M. (1991). Alzheimers disease and family caregiving: Critical synthesis of the literature and research agenda. Nursing Research, 40, 331-337.

LaRue, A., Bank, L., \& Jarvik, L. (1979). Health in old age: How do physicians' ratings and self-ratings compare? Journal of Gerontology, 34, 687.

Lawton, M., Rajagopal, D., Brody, T., \& Kleban, M. (1992). The dynamics of caregiving for a demented elder among black and white families. Journal of Gerontology: Social Sciences, 27, S156-64.

Lazarus, R., \& Folkman, S. (1984). Stress, appraisal, and coping. New York: Springer.

Leight, S. (2003). The application of a vulnerable populations conceptual model to rural health. Public Health Nursing, 20(6), 440-448.

Levine, C., Gibson-Hunt, G., Halper, D., Hart, A., Lautz, J., \& Gould, D. (2005). Young adult caregivers: A first look at an unstudied population. American Journal of Public Health, 95(11), 2071-2075.

Link, B. G., \& Phelan, J. C. (1996). Understanding sociodemographic differences in health-the role of fundamental social causes. American Journal of Public Health, $86,471-473$.

Lipton, R., Liao, Y., Cao, G., Cooper, R., \& McGee, D. Determinants of incident noninsulin-dependent diabetes mellitus among Blacks and Whites in a national sample. American Journal of Epidemiology, 138, 826-839.

LoGuidice, D., Kerse, N., Brown, K., \& Gibson, S. (1998). The psychosocial health status of caregivers of persons with dementia: A comparison with the chronically ill. Quality of Life Research, 7, 345-351. 
Mace, N., \& Rabins, P. (2001). The 36-hour day: A family guide to caring for persons wtih alzheimer's disease, related dementing illnesses, and memory loss in later life $\left(4^{\text {th }}\right.$ ed.). The Johns Hopkins University Press.

Macera, C. A., Eaker, E. D., Goslar, P. W., Deandrade, S. J., Williamson, J. S., Cornman, C., \& Jannarone, R. J. (1992). Ethnic differences in the burden of caregiving. American Journal of Alzheimer's Disease, 7, 4-7.

Markovitz, J., Matthews, K., Wing, R., Kuller, L., \& Meilahn, E. (1991). Psychological, biological, and health behavior predictors of blood pressure changes in middleaged women. Journal of Hypertension, 9(5), 399-406.

McConnell, C. (1994). Impact of spouse caregiving on health behaviors and physical and mental health status. The American Journal of Alzheimer's Care and Related Disorders \& Research., 9, 26-36.

McConnell, C., \& Gibson, G. (1997). Racial, ethnic, and cultural differences in dementia caregiving: Review and analysis. The Gerontologist, 37(3), 355-364.

McDonald, P. E., Brennan, P. F., \& Wykle, M. L. (2005). Perceived health status and health-promoting behaviors of African-American and White informal caregivers of impaired elders. Journal of National Black Nurses' Association, 16(1), 8-17.

McDonald, P., Fink, S., \& Wykle, M. (1999). Self-reported health-promoting behaviors of Black and White caregivers. Western Journal of Nursing Research, 21(4), 538548.

McDonald, P. \& Wykle, M. (2003). Predictors of health-promoting behaviors of African American and White caregivers of impaired elders. Journal of National Black Nurses Association, 14(1), 1-12.

McKinlay, J., Crawford, S., \& Tennstedt, S. (1995). The everyday impacts of providing informal care to dependent elders and their consequences for the care recipients. Journal of Aging and Health, 7(4), 497-528.

Miller, B., Campbell, R., Farran, C., Kaufman, J. \& Davis, L. (1995). Race, control, mastery, and caregiver distress. Journal of Gerontology: Social Sciences, 50B, S374-S382.

Mossey, J. M., \& Shapiro, E. (1982). Self-rated health: A predictor of mortality among the elderly. American Journal of Public Health, 72, 800.

Mui, A. (1992). Caregiver strain among Black and White daughter caregivers: A role theory perspective. The Gerontologist, 32(2), 203-212. 
Mutran, E. (1985). Intergenerational family support among Blacks and Whites: Response to culture or to socioeconomic differences. Journal of Gerontology, 40(3), 382389.

National Alliance for Caregiving and the American Association of Retired Persons (2004). Family caregiving in the U.S.: Findings from a national survey. Bethesda, MD: National Alliance for Caregiving.

National Family Caregivers Association. (2000). Random sample survey of family caregivers. Retrieved July 2, 2007 from http://www.thefamilycaregiver.org/who are family caregivers/care giving_statst ics.cfm

National Institutes of Health. National Institutes of Diabetes \& Digestive \& Kidney Diseases. (2006). Treatment methods for kidney failure: Hemodialysis. Betheseda, M. D. Retrieved August 20, 2007 from http://kidney.niddk.nih.gov/kudiseases/pubs/pdf/hemodialysis.pdf

Neal, M., Chapman, N., \& Ingersoll-Dayton, B. (1993). Balancing work and caregiving for children, adults, and elders. Newbury Park, CA: Sage Publications.

Ory, M., Hoffman, R. R., Yee, J. L., Tennstedt, S., \& Schultz, R. (1999). Prevalence and impact of caregiving: A detailed comparison between dementia and nondementia caregivers. The Gerontologist, 39, 177-185.

Pearlin, L., Mullan, J., Semple, S., \& Skaff, M. (1990). Caregiving and the stress process: An overview of concepts and their measures. The Gerontologist, 30(583-594).

Pender, N., Murdaugh, C., \& Parson, M. (2005). Health promotion in nursing practice (5th ed.). Prentice Hall.

Phillips, C. A. (1992). Vulnerability in family systems: Application to antepartum. Journal of Perinatal and Neonatal Nursing, 6(3), 26-36.

Phillips, L. R., \& Rempusheski, V. F. (1986). Caring for the frail elderly at home: Toward a theoretical explanation of the dynamics of poor family caregivers. Advances in Nursing Science, 8 (4), 62-84.

Picot, S. (1995). Rewards, costs, and coping of African American caregivers. Nursing Research, 44, 147-152.

Picot, S., \& Genet, C. (1998). Behavior upset in hypertensive and normotensive Black female caregivers. Clinical Excellence for Nurse Practitioners, 2(1), 23-9. 
Picot, S., Zauszniewski, J., Debanne, S., \& Holston, E. (1999). Mood and blood pressure responses in Black female caregivers and noncaregivers. Nursing Research, 40(3), 150-161.

Picot, S., Zauszniewski, J., Delgado, C. (1997). Cardiovascular responses of African American female caregivers. Journal of Black Nurses Association, 9(1), 3-21.

Pinquart, M. \& Sorensen, S. (2003). Differences between caregivers and noncaregivers in psychological health and physical health: A meta-analytic comparison. Aging and Mental Health, 8, 438-449.

Pinquart, M., \& Sorensen, S. (2005). Ethnic differences in stressors, resources, and psychological outcomes of family caregiving: A meta-analysis. The Gerontologist, 45(1), 90-106.

Pratt, C., Schmall, V., Wright, S. \& Cleland, M. (1985). Burden and coping strategies of caregivers to Alzheimer's patients. Family Relations, 34, 27-33.

Pruchno, R. A., \& Potashnik, S. L. (1989). Caregiving spouses: Physical and mental health in perspective. Journal of American Geriatric Society, 37, 697-705.

Radloff, L. (1997). The CES-D scale, a self-report depression scale for researching the general population. Applied Psychological Measurement, 1, 385-401.

Raveis, V. \& Karus, D. (1999). Elderly cancer patients: correlates of depressive symptomatology. Journal of Psychosocial Oncology, 17(2), 55-77.

Rogers, A. C. (1997). Vulnerability, health and health care. Journal of Advanced Nursing, 26, 65-72.

Rosenman, L., Le Brocque, R., \& Carr, S. (1994). The impact of caring upon the health of older women. Australian Journal of Public Health, 18(4), 440-444.

Sales, E. (2003). Family burden and quality of life. Quality of Life Research, 12 Suppl 1, $33-41$.

Sarkisian, C., Liu, H., Enrsrud, K., et al. (2001). Correlates of attribution of new disability to 'old age.' Journal of American Geriatric Society, 49, 134-141.

Schultz, R., \& Beach, S. (1999). Caregiving as a risk factor for mortality. JAMA, 282(23), 2215-2219.

Schultz, R., Newsom, J., Mittelmark, M., Burton, L., Hirsch, C., \& Jackson, S. (1997). Health effects of caregiving: The caregiver health effects study: An ancillary study of the cardiovascular health study. Annuals of Behavioral Medicine, 19, 110-116. 
Schulz, R., O’Brien, A., Bookwala, J., \& Fleissner, K. (1995). Psychiatric and physical morbidity effects of dementia caregiving: Prevalence, correlates, and causes. The Gerontologist, 35, 771-791.

Schultz, R., \& Quitnner, A. L. (1998). Caregiving for children and adults with chronic conditions: Introduction to the special issue. Health Psychology, 17, 107-111.

Shifren, K. (2001). Early caregiving and adult depression: Good news for young caregivers. The Gerontologist, 41, 188-190.

Shifren, K., \& Kachorek, L. (2003). Does early caregiving matter? The effects on young caregivers' adult mental health. International Journal of Behavioral Development, 27, 338-346.

Shua-Haim, J., Haim, T., Shi, Y., Kuo, Y., \& Smith, J. (2001). Depression among alzheimer's caregivers: Identifying risk factors. American Journal of Alzheimers Disease and Other Dementias, 16, 353-359.

Sleath, B., Thorpe, J., Landerman, L., Doyle, M., \& Clipp, E. (2005). African American and White caregivers of older adults with dementia: Differences in symptomatology and psychotropic drug use. Journal of American Geriatric Society, 253(3), 397-404.

Snyder, B. \& Keefe, K. (1985). The unmet needs of family caregivers for frail and disabled adults. Social Work Health Care, 10, 1-14.

Song, L., Biegel, D., \& Milligan, S. (1997). Predictors of depressive symptomatology among lower social class caregivers of persons with mental illness. Community Mental Health J, 33(4), 269-286.

Sorensen, S., \& Pinquart, M. (2005). Racial and ethnic differences in the relationship of caregiving stressors, resources, and sociodemographic variables to caregiver depression and perceived physical health. Aging Mental Health, 9(5), 482-495.

Sotomayor, M., \& Randolph, S. (1988). A preliminary review of caregiving issues and the Hispanic family. In M. Sotomayor and H. Curiel (Eds.), Hispanic elderly: A cultural signature (pp. 137-162). Edinburg: Pan American University Press.

Suh, E., Diener, E., \& Fujita, F. (1996). Events and subjective well-being: Only recent events matter. Journal of personality and social psychology, 70, 1091-1102.

Turner, H. A., \& Catania, J. A. (1997). Informal caregiving to persons with aids in the United States: Caregiver burden among central cities residents eighteen to fortynine years old. American Journal of Community Psychology, 25, 35-59. 
Underwood, S., Buseh, A., Canales, M., Powe, B., Dockery, B., Kather, T., \& Kent, N. (2005). Nursing contributions to the elimination of health disparities among African Americans: Review and critique of a decade of research-Part III. Journal of National Black Nurses Association, 16(2), 35-58.

United States Department of Health and Human Services. (2004). National Healthcare Disparities Report. Rockville, MD: U.S. Department of Health and Human Services, Agency for Health Care Research and Quality.

U. S. Renal Data System: USRDS 2003 Annual Data Report. National Institutes of Health. National Institutes of Diabetes and Digestive and Kidney Disease. Betheseda, M. D.

U. S. Renal Data System: USRDS 2006 Annual Data Report. National Institutes of Health, National Institutes of Diabetes and Digestive and Kidney Disease. Betheseda, M. D.

U. S. Renal Data System: USRDS 2006 Annual Data Report. National Institutes of Health, National Institutes of Diabetes and Digestive and Kidney Disease. Betheseda, M. D.

Vitaliano, P. P., Schulz, R., Kiecolt-Glaser, J., \& Grant, I. (1997). Research on physiological and physical concomitants of caregiving: Where do we go from here? Annals of Behavioral Medicine, 19, 117-123.

Vitaliano, P., Zhang, J., \& Scanlan, J. (2003). Is caregiving hazardous to one's physical health? A meta-analysis. Psychological Bulletin, 129(6), 946-972.

Ware, J. E., \& Karmos, A. H. (1976). Development and validation of scales to measure perceived health and patient role propensity. Carbondale, IL: Southern Illinois, University School of Medicine.

White, Y. \& Greyner, B. (1999). The biopsychosocial impact of end stage renal disease: The experience of dialysis patients and their partners. Journal of Advanced Nursing, 30(6), 1312-1322.

Wicks, M., Milstead, E., Hathaway, D., \& Cetingok, M. (1997). Subjective burden and quality of life in family caregivers of patients with end stage renal disease. ANNA Journal, 24(5), 527-528.

Wilcox, S., Bopp, M., Wilson, D., Fulk, L., \& Hand, G. (2005). Race differences in cardiovascular and cortisol responses to an interpersonal challenge in women who are family caregivers. Ethnicity \& Disease, 15, 17-24. 
Williams, D. \& Wilson, C. (2001). Race, ethnicity, and aging. In R. H. Binstock \& L.K. George (Eds.), Handbook of aging and the social sciences $\left(4^{\text {th }}\right.$ ed., pp. 160-178). San Diego: Academic Press.

World Health Organization (1948). The first ten years of World Health Organization. World Health Organization, Geneva.

Wykle, M. \& Segall, M. (1991). A comparison of Black and White family caregivers' experience with dementia. Journal of the National Black Nurses Association, 5, $29-41$.

Zhang, J., Vitaliano, P., \& Lin, H. (2006). Relations of caregiving stress and health depend on the health indicators used and gender. International Journal of Behavioral Medicine, 13(2), 173-181.

Zich, J.M. Attkisson, C.C. \& Greenfield, T.K. (1990). Screening for depression in primary care clinics: The CES-D and the BDI. International Journal of Psychiatry in Medicine, 20, 259-277. 
APPENDICES 


\section{APPENDIX A. CAREGIVER DEMOGRAPHIC DATA FORM}

Caregiver's Initials

Caregiver Age

Patient Initials

Patient Age

Marital Status of Caregiver: (circle one answer)

$\begin{array}{llll}\text { Single } & \text { Married } & \text { Divorced } & \text { Widowed }\end{array}$

Caregiver Gender: Male $\quad$ Female Patient Gender: Male Female

Caregiver Race Patient Race

Caregiver Employment Status: (circle one answer)

Full-time Part-time Unemployed Retired Homemaker

Student

Patient Employment Status: (circle one answer)

Full-time Part-time Unemployed Retired Homemaker

Student

Caregiver Occupation

Caregiver Years of Education

Caregiver Annual Income (include total income of family if shared) $\$$

Has your income decreased since caring for the patient? Yes No

What is the caregiver's relationship to patient: (circle one answer)

Spouse Child Parent Sibling Other

Does caregiver live with the patient: (circle one answer) Yes No

Who assists the patient with activities of daily living on most days: (circle one answer)

1. No assistance needed

2. Caregiver

3. Other family or friend living in the household

4. Other family or friend living outside the household

5. Professional or Health Care Worker

Go to the next page 


\section{$\mathrm{CDDF}$}

How many years has the caregiver been providing care to the patient?

How long has the caregiver been married to the patient? years

What dialysis type does patient receive? (circle one answer)

In-center hemodialysis

Home hemodialysis

Continuous Ambulatory Peritoneal Dialysis

How satisfied are you with the support that you get from family and friends? (circle one answer)

$\bullet$ Very Satisfied $\bullet$ Satisfied $\bullet$ Somewhat Satisfied $\bullet$ Dissatisfied $\bullet$ Very Dissatisfied

You Have Completed this Questionnaire 


\section{APPENDIX B. CAREGIVERS' PERCEIVED HEALTH ASSESSMENT FORM}

Circle your response to the question.

There are no right or wrong answers.

I. Regarding your health, how many times have you visited a healthcare provider (i.e., physician, nurse practitioner) within the past 6 months?
(1) 0 - 1 times
(2) 2 - 3 times
(3) 4 - 5 times
(4) greater than 5 times

II. How would you rate your overall health?

Excellent

Very good

Good

Fair

Poor

You Have Completed this Questionnaire 


\section{APPENDIX C. SEVERITY OF CAREGIVER'S DISEASE SCALE}

\section{CAREGIVER'S HEALTH}

Caregiver's Height (in inches)

Caregiver's Weight (in pounds)

\section{CURRENT and PAST Health Problems}

Note: Please refer to General Demographic/Health Problems form (the pages that you were told to tear out) for key to current and past health problems.

How much does it stand in the way of what you do?

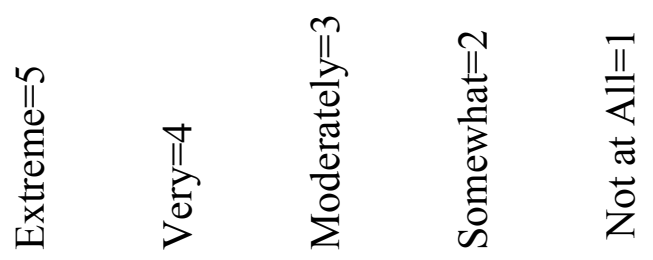

Problem

Type

Cardiovascular

(including hypertension)

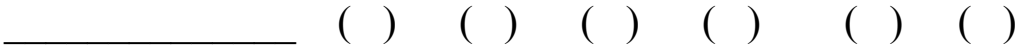

Respiratory

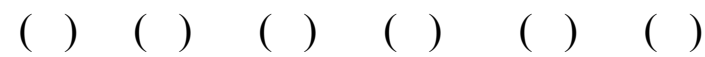

Peripheral Vascular ( ) ( ) ( ) ( ) ( ) ( )

Nervous System (including stroke)

Urinary

Gastrointestinal

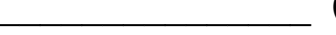




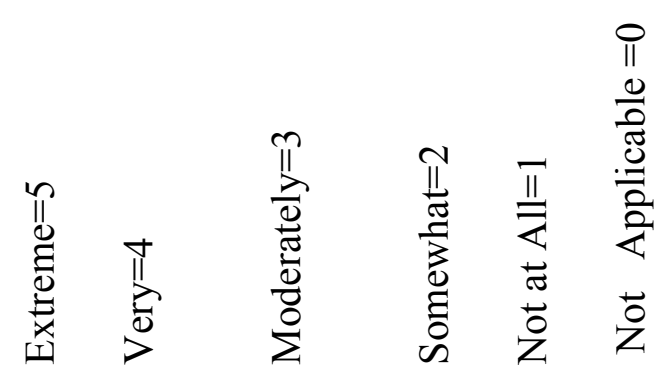

Endocrine

(including diabetes)

Muscle \& Bone (including

arthritis and back problems

Female/Male Problems

Other

Other

Other

Other

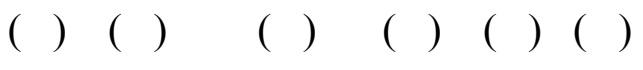

( ) ( ) ( ) ( ) ( ) ( )

( ) ( ) ( ) ( ) ( ) ( )

( ) ( ) ( ) ( ) ( ) ( )

( ) ( ) ( ) ( ) ( ) ( )

( ) ( ) ( ) ( ) ( ) ( )

()()$\quad()()()$

Of those things you've listed, which one bothers you the most?

What medications are you now taking that were ordered by a doctor?

Medication

Example:

1.

2.

3.

4.

5.

Insulin

Reason

.

.

Please Turn to the Next Page
Diabetes 
7.

8.

9.

10.

Note: If more than 10 medications, continue list on back of this page.

What other things are you taking?

Prompts: Vitamins? Ointments/creams? Eyedrops? Liquor/beer? Home remedies?

Item

Reason

1.

2.

3.

4.

5.

Note: If more than 5 other things, continue list on back of this page.

How many times have you been to the doctor's office in the past 6 months?

How many day in the past 6 months have you been confined to home because of illness?

How many times in the past 6 months have you been in the hospital? Inpatient Outpatient Emergency room

How many days in the past 6 months have you been hospitalized?

Inpatient Emergency room

Please Turn to the Next Page 
What do you do for yourself to stay healthy?

1.

2.

Note: If more than 6 things, continue list on back of this page.

Prompt: Is there anything else you do that makes you feel good?

Please Turn to the Next Page 


\section{CHANGES IN CAREGIVER'S HEALTH}

Directions: Tell me how each of the following has changed as a result of you becoming a caregiver. First, mark the extent of change by placing an (X) on the line of your choice. Second, mark the type of change (good or bad) by placing an (X) on the line.

Extent of Change

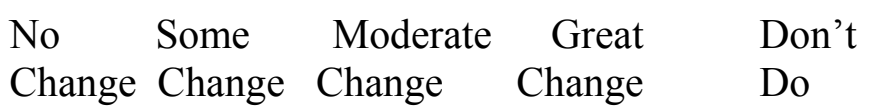

Quality of food

that I eat

Amount of food

that I eat

Exercise

Weight

Amount of sleep

Quality of sleep

Smoking

Alcohol intake

Self-confidence

Respect for myself

Mood

Worry
Type of Change

Good Bad

(1) 
Extent of Change

Type of Change

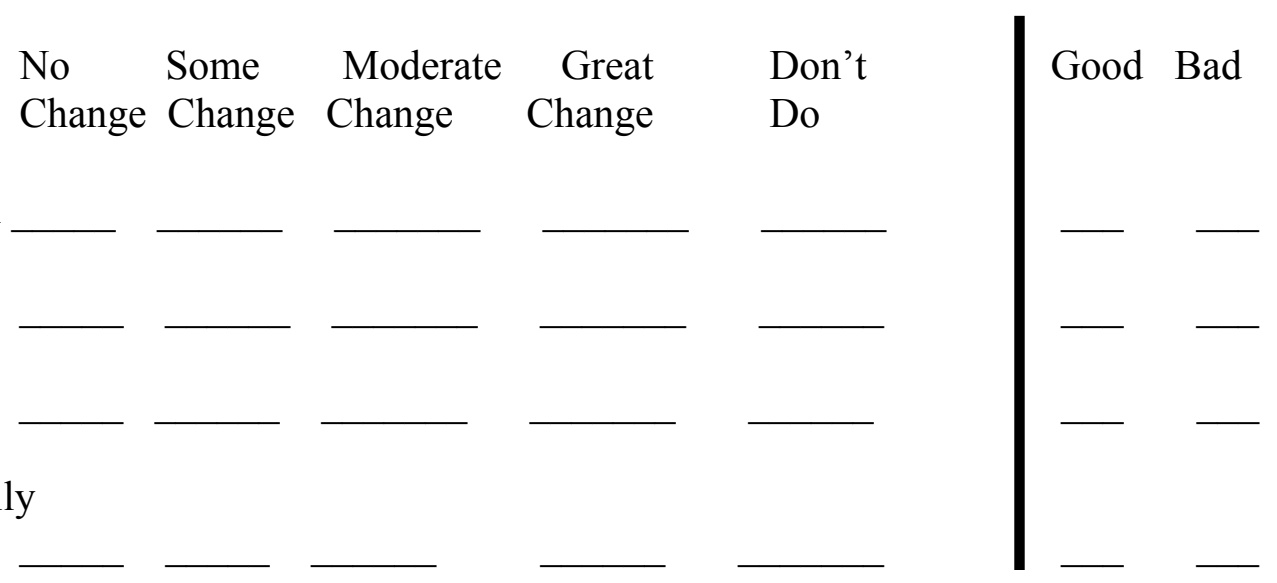

You Have Completed this Questionnaire. 


\section{APPENDIX D. CENTER FOR EPIDEMIOLOGICAL STUDIES-DEPRESSION SCALE (CES-D)}

Instructions for questions: Below is a list of ways you might have felt or behaved. Please tell me how often you felt this way during the past week.

$\begin{array}{lrrr}\text { Rarely or } & \text { Some or a } & \text { Occasionally } & \text { Most or } \\ \text { none of } & \text { little of the } & \text { or a moderate } & \text { all of the } \\ \text { the time } & \text { time } & \text { amount of the time }\end{array}$

During the past week: $\quad$ (less than 1 day) (1-2 days) time (3-4 days) (5-7 days)

1. I was bothered by things

that usually don't bother me 0

1

2

3

2. I did not feel like eating:

my appetite was poor

0

1

2

3

I felt that I could not shake

off the blues even with the help

from my family or friends 0

1

2

3

I felt that I was just as good

as other people

0

1

2

3

I had trouble keeping my

mind on what I was doing

0

1

2

3

6. I felt depressed

0

1

2

3

7. I felt that everything I did was an effort 0

8. I felt hopeful about the future

9. I thought my life had been

a failure

10. I felt fearful

11. My sleep was restless

0

12. I was happy

0

1
2

3

3

Please Turn to the Next Page 
Instructions for questions: Below is a list of ways you might have felt or behaved. Please tell

me how often you felt this way during the past week.

\begin{tabular}{|c|c|c|}
\hline $\begin{array}{l}\text { Rarely or } \\
\text { none of } \\
\text { the time }\end{array}$ & $\begin{array}{l}\text { Some or a } \\
\text { little of the } \\
\text { time }\end{array}$ & $\begin{array}{l}\text { Occasionally } \\
\text { or a moderate } \\
\text { amount of the }\end{array}$ \\
\hline
\end{tabular}

During the past week (less than 1 day) (1-2 days) time (3-4 days) (5-7 days)

13. I talked less than usual $0 \quad 1 \quad 2$

14. I felt lonely $\quad 0 \quad 1 \quad 2203$

15. People were unfriendly $\quad 0 \quad 1 \quad 2 \quad 3$

16. I enjoyed life $\quad 0 \quad 1123$

17. I had crying spells $\quad 0 \quad 1123$

$\begin{array}{lllll}\text { 18. I felt sad } & 0 & 1 & 2 & 3\end{array}$

19. I felt that people dislike $\quad 0 \quad 113$

20. I could not get "going” $\quad 0 \quad 1 \quad 3$

(C) 1977. West Publishing Company Co. Applied Psychological Measurement, Inc. Reverse score 4, 8, 12, 16

You Have Completed this Questionnaire. 


\section{APPENDIX E. LETTER OF APPROVAL - INSTITUTIONAL REVIEW BOARD}

Principal Investigator: $\quad$ Dina Byers, MSN, RN
$\frac{\text { Brief Project Title: Predictors of Perceived Health Status of African American Women who are }}{\text { Family Caregivers of Persons with ESRD }}$

$$
\text { H. } 20 \%
$$

IRB ACTION:

Approved _._.

Approved w/proviso(s)

Referred For Board Review

COMMENTS: This study qualifies for exempt status under 45CFR46.101(b)(4). Informed consent is waived in accord with 45CFR46.116(d).

Consent Required: No: $\checkmark$ Yes: Not Applicable: Written

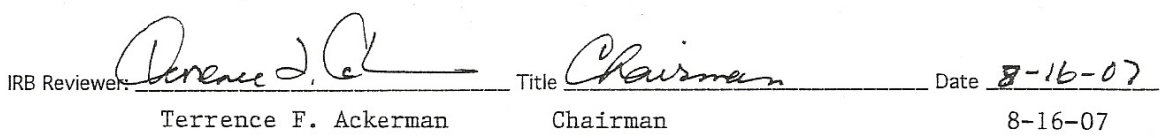




\section{VITA}

Dina Jo Byers was born in Princeton, Kentucky on September 10, 1974. She graduated from Caldwell County High School in Princeton, Kentucky, and later attended Murray State University in Murray, Kentucky where she earned a BSN in 1999. She worked as a staff nurse in an ambulatory surgery and endoscopy unit at Jennie Stuart Medical Center in Hopkinsville, Kentucky. She entered the master's program in nursing at Murray State University in August 2001 and graduated in 2004. She taught in the Practical Nursing program at Hopkinsville Community College in Hopkinsville, Kentucky from June, 2001 until August 2002. She began working at the University of Kentucky Medical Center in Lexington, Kentucky while completing her master's degree at Murray State. Her thesis research explored the lived experience of registered nurses caring for patients with dementia in the acute care setting. After graduation in 2004, she began teaching at Murray State University. In 2005, Dina was accepted into the Nursing doctoral program at The University of Tennessee Health Science Center in Memphis, Tennessee. Her dissertation research focused on the predictors of African American women's perceived health status in the context of caring for a relative with end stage renal disease. She will graduate with a Doctor of Philosophy in nursing degree in May 2008. Presently she is employed with Murray State University. 